\title{
Targeting RTN4/NoGo-Receptor reduces levels of ALS protein ataxin-2
}

Caitlin M. Rodriguez ${ }^{1}$, Sophia C. Bechek ${ }^{1}$, Graham L. Jones ${ }^{2}$, Lisa Nakayama ${ }^{1}$, Tetsuya

Akiyama $^{1}$, Garam Kim ${ }^{1,3}$, David E. Solow-Cordero ${ }^{4}$, Stephen M. Strittmatter ${ }^{5}$, Aaron D. Gitler ${ }^{1,6}$

${ }^{1}$ Department of Genetics, Stanford University School of Medicine, Stanford, CA, USA

${ }^{2}$ Department of Neurosurgery, Stanford University School of Medicine, Stanford, CA, USA

${ }^{3}$ Stanford Neurosciences Interdepartmental Program, Stanford University School of Medicine,

Stanford, CA, USA

${ }^{4}$ High-Throughput Bioscience Center, Department of Chemical and Systems Biology, Stanford

University, Stanford, CA, USA

${ }^{5}$ Program in Cellular Neuroscience, Neurodegeneration and Repair, Yale University School of

Medicine, New Haven, CT, USA

${ }^{6}$ Correspondence should be addressed to: A.D.G.

Aaron D. Gitler

Department of Genetics

Stanford University

300 Pasteur Drive

M322 Alway Building

Stanford, CA 94305

650-725-6991 (phone)

agitler@stanford.edu 


\section{Summary}

Gene-based therapeutic strategies to lower ataxin-2 levels are emerging for neurodegenerative diseases amyotrophic lateral sclerosis (ALS) and spinocerebellar ataxia type 2 (SCA2). To identify additional ways of reducing ataxin-2 levels, we performed a genome-wide screen in human cells for regulators of ataxin-2 and identified $R T N 4 R$, the gene encoding the RTN4/NoGo-Receptor, as a top hit. RTN4R knockdown, or treatment with a peptide inhibitor, was sufficient to lower ataxin2 protein levels in mouse and human neurons in vitro and Rtn4r knockout mice have reduced ataxin-2 levels in vivo. Remarkably, we observed that ataxin-2 shares a role with the RTN4/NoGoReceptor in limiting axonal regeneration. Reduction of either protein increases axonal regrowth following axotomy. These data define the RTN4/NoGo-Receptor as a novel therapeutic target for ALS and SCA2 and implicate the targeting of ataxin-2 as a potential treatment following nerve injury.

\section{Introduction}

ALS is a rapidly progressive neurodegenerative disease characterized by loss of motor neurons from the brain and spinal cord. Loss of motor neurons leads to muscle weakness, paralysis, and eventual death 3-5 years following diagnosis (Taylor et al., 2016). SCA2 is associated with loss of Purkinje neurons from the cerebellum, which affects balance and coordination, and causes slow saccadic eye movements and cognitive impairment (Paulson et al., 2017). SCA2 is an autosomal dominant genetic disorder caused by long CAG repeat expansions ( $>34)$ in the ATXN2 gene, which encodes the ataxin-2 protein (Scoles and Pulst, 2018). Alternatively, intermediate length repeat expansions (27-33) in ATXN2 are a genetic risk factor for ALS (Elden et al., 2010). Therapeutic strategies to target ataxin-2 have shown efficacy in preclinical studies (Becker et al., 2017, Scoles et al., 2017), motivating the initiation of a clinical trial testing ATXN2-targeting antisense oligonucleotides (ASOs) in human ALS patients (ClinicalTrials.gov identifier: NCT04494256).

\section{Results}

Whole-genome siRNA screen identifies genes and cellular pathways that regulate ataxin-2 levels To discover additional targets and pathways to lower ataxin-2 levels, we created a quantitative and highly sensitive reporter of endogenous ataxin-2 protein levels by inserting a HiBiT tag on the C- 
terminus of ataxin-2 in HEK293T cells using CRISPR-Cas9 genome editing (Figure 1A). HiBiT is an 11-amino acid peptide subunit of the NanoBiT luciferase enzyme that is inert on its own but binds with high affinity to $\operatorname{LgBiT}$, reconstituting NanoBiT (Dixon et al., 2016). This allows for easy and specific detection of ataxin-2 using an antibody-free blotting method (Figure 1B-D). An in-well reaction of ataxin-2-HiBiT cell lysate with the exogenous addition of LgBiT and the furimazine substrate generates quantifiable bioluminescence as a direct measure of ataxin-2 abundance (Figure 1E). In parallel, we stably incorporated firefly luciferase (FFluc) into the ataxin-2-HiBiT line to normalize for protein abundance.

We used the ataxin-2-HiBiT cell line to perform a genome-wide screen using arrayed siRNA pools targeting 21,121 mRNA transcripts (Figure 1F, 1G, and S1). We performed the screen in duplicate for both ataxin-2-HiBiT levels and FFluc levels, a control for ruling out siRNAs with nonspecific effects on gene expression. We classified siRNAs that had an average HiBiT Z-score less than -1.65 and an average FFluc Z-score greater than -1 as a hit that decreased ataxin-2resulting in 348 primary screen hits (Supplementary Data Table 1). We selected primary screen hits for validation based on function in shared pathways (e.g., splicing) or known roles in the nervous system. We performed a secondary validation screen using 102 siRNA pools, of which 77 validated and we classified these as "high confidence hits" (Figure S1C, Table S1).

Gene ontology analysis of the primary screen hits revealed an enrichment in constituents of the pre-mRNA splicing pathway (Figure 1H and 1I), and 36 of the 77 high confidence hits have roles in the major spliceosome complexes (Figure 1J). These proteins are enriched for the like-Sm or LSm domain (Figure S2), a protein domain critical for complex formation and splicing activity (He and Parker, 2000). Ataxin-2 has an LSm domain that is one of the few predicted structured regions of this largely disordered protein. We independently validated several high confidence hits using siRNAs in unedited HEK293T cells and immunoblotting for ataxin-2 (Figure 1K, 1L, and S3A). We also performed RT-qPCR and found that some of these hits affected steady-state ATXN2 mRNA levels (Figure S3B). The presence of a shared LSm domain combined with the regulation revealed by this screen suggests a potential functional connection between ataxin- 2 and the spliceosome. 
Knockdown or inhibition of the RTN4/NoGo-Receptor lowers ataxin-2 levels

Because splicing is an essential cellular process and splicing defects contribute to ALS (LagierTourenne et al., 2010), we sought to identify the optimal target with therapeutic potential by filtering high confidence hits for essentiality (DepMap database, average gene effect $>-1$ ) (Meyers et al., 2017, McFarland et al., 2018) and central nervous system expression (GTEx database, cortical pTPM>15) (2013) (Figure 2A). We reasoned that selecting targets with high nervous system specificity may eliminate potential negative off-target effects in non-diseased tissues. Following these filtering steps, the top hit was $R T N 4 R$, the gene that encodes RTN4/NoGoReceptor. RTN4/NoGo-Receptor has been implicated in axon regeneration, sprouting, and plasticity (Fournier et al., 2001, McGee et al., 2005, Wang et al., 2020, Wang et al., 2011, Akbik et al., 2013, Bhagat et al., 2016, Kim et al., 2004, Fink et al., 2015), and targeting its ligand NoGoA modulates mutant SOD1 mouse models of ALS (Jokic et al., 2006, Bros-Facer et al., 2014, Fournier et al., 2001, Yang et al., 2009). RTN4/NoGo-Receptor has several glia- and neuronderived ligands including the three gene products of the RTN4 gene-NoGo-A, B, and C-as well as oligodendrocyte myelin glycoprotein (OMgp) and myelin-associated glycoprotein (MAG) (Schwab, 2010, Domeniconi et al., 2002, Wang et al., 2002). Other high-affinity ligands include BAI adhesion-GPCRs (Wang et al., Chong et al., 2018), LGI1 (Thomas et al., 2010), BLyS (Zhang et al., 2009), and LOTUS (Sato et al., 2011). RTN4R knockdown reduced ataxin-2 levels by HiBiT assay and immunoblot (Figure 2B-D). We confirmed this in SH-SY5Y neuroblastoma cells (Figure S4A and S4B). Conversely, knockdown of ataxin-2 had no effect on RTN4/NoGoReceptor levels (Figure S4C and S4D). This effect seems specific to ataxin-2 and not polyQ proteins in general because knocking down $R T N 4 R$ did not affect expression levels of polyQ disease proteins huntingtin and ataxin-3 nor the ataxin-2 paralog ATXN2L (Figure S5). As another functional readout of decreased ataxin-2 function (Becker et al., 2017), RTN4R knockdown reduced recruitment of TDP-43 to stress granules (Figure S6). These data provide evidence that RTN4/NoGo-Receptor is required to maintain ataxin-2 levels.

Regulation of ataxin-2 by RTN4/NoGo-Receptor occurs at the protein level because RTN4R knockdown did not affect $A T X N 2$ mRNA levels (Figure 2E and 2F). The HiBiT system allows for monitoring protein degradation (Riching et al., 2018). We used the ataxin-2-HiBiT line to test if $R T N 4 R$ knockdown leads to ataxin-2 protein degradation by the proteasome or autophagy. 
Following siRNA knockdown of RTN4R, treatment of cells with a proteasome inhibitor (Figure 2G), but not an autophagy inhibitor (Figure S7A), resulted in an increase in ataxin-2 to levels comparable to the non-targeting control, indicating that ataxin-2 is degraded by the proteasome. $R T N 4 R$ knockdown did not increase 20S proteasome activity (Figure S7B), suggesting a specific effect on ataxin-2 proteasomal degradation caused by RTN4R knockdown.

NEP1-40 is a peptide that acts as a competitive RTN4/NoGo-Receptor antagonist. It is a fragment of the luminal region of NoGo-A, B and C that binds to RTN4/NoGo-Receptor to prevent ligand signaling (Figure 2H) (GrandPré et al., 2002). NEP1-40 treatment decreased ataxin-2 levels in the ataxin-2-HiBiT cells (Figure 2I). Thus, targeting RTN4R by either genetic knockdown or with a peptide inhibitor leads to decreased levels of ataxin-2.

Knockdown or inhibition of the RTN4/NoGo-Receptor lowers ataxin-2 levels in mouse and human neurons

To extend our findings to neurons, we tested this interaction in mouse cortical neurons and human iPSC-derived neurons (iNeurons) (Figure 3A and 3B) (Bieri et al., 2019). Treatment of mouse cortical neurons and human iNeurons with lentiviruses expressing shRNA targeting mouse or human $R T N 4 R$ respectively resulted in about a 50\% reduction of ataxin-2 (Figure 3C-F), without affecting levels of ATXN2 mRNA (Figure S8). Application of the NEP1-40 inhibitor peptide caused a dose-dependent reduction of ataxin-2 in both mouse cortical neurons and human iNeurons (Figure 3G-L). These results suggest that targeting RTN4/NoGo-Receptor, either genetically or with a peptide inhibitor, is sufficient to markedly decrease levels of ataxin-2 in neurons. Finally, we tested the effects of RTN4/NoGo-Receptor on ataxin-2 levels in vivo. We analyzed heterozygous and homozygous $R \operatorname{tn} 4 r$ knockout mice. These mice are fertile and viable with no apparent deficits to the nervous system (Kim et al., 2004). We observed a dose-dependent reduction in ataxin-2 in lysates from mouse cortex from the Rtn4r heterozygous and homozygous knockout mice compared to wild-type mice (Figure 3M and 3N), showing that reduction of the RTN4/NoGo-Receptor is sufficient to lower levels of ataxin-2 in the nervous system.

Knockdown of ataxin-2 improves axon regrowth after injury 
RTN4/NoGo-Receptor signaling destabilizes the actin cytoskeleton leading to growth cone collapse, limiting neurite outgrowth (Chivatakarn et al., 2007, Schwab, 2010, Montani et al., 2009). Reduction or inhibition of RTN4/NoGo-Receptor or its ligands has been shown to limit axonal regeneration following injury (Wang et al., 2020, Wang et al., 2011, Kim et al., 2004, Fink et al., 2015, Fournier et al., 2001, Schwab and Strittmatter, 2014). Since we have demonstrated that knocking down or inhibiting RTN4/NoGo-Receptor lowers ataxin-2, we tested if reducing ataxin-2 levels is sufficient to promote axon regeneration, perhaps functioning downstream of RTN4/NoGo-Receptor. We plated primary mouse neurons in the soma compartment of microfluidics chambers (Figure 4A), treated with lentivirus expressing shRNA targeting either Atxn2 or Rtn4r at DIV5 (Figure 4B), and allowed neurons to mature and project axons through the microchannels and into the inner chamber of the axonal compartment. At DIV17, we performed vacuum-assisted axotomy to fully sever axons projecting into the inner chamber (Figure 4C) and permitted neurons to regenerate axons for $48 \mathrm{hr}$. We analyzed Tuj1-stained axons and found that the average length of regrown axons was markedly increased in either the Rtn4r or Atxn2

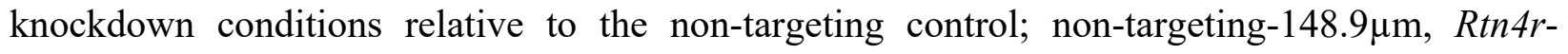
188.8 $\mu \mathrm{m}$, and Atxn2-184.8 $\mu \mathrm{m}$ (Figure 4D and 4E). These results provide evidence of a role for ataxin-2 in limiting regeneration after nerve injury and present ataxin-2 as a potential therapeutic target following nerve injury. Additionally, this finding provides further evidence that RNAbinding proteins that drive RNA granule formation following stress can limit axon regenerationas has been reported for TIAR-2 (Andrusiak et al., 2019, Becker et al., 2017, Liu-Yesucevitz et al., 2011).

\section{Discussion}

Here we performed an unbiased genome-wide screen and discovered RTN4/NoGo-Receptor as a novel regulator of ataxin-2 levels. We provide evidence that RTN4R functions upstream of ataxin2. Since ataxin-2 has been implicated in two neurodegenerative diseases-ALS and SCA2efforts are underway to target it therapeutically including the use of ASOs targeting ATXN2 (Becker et al., 2017, Scoles et al., 2017). Together with the accompanying manuscript by Kim et al. identifying Etidronate, a potent small molecule inhibitor of ataxin-2 levels (please see accompanying manuscript), we now present an additional way to reduce ataxin-2 levels. RTN4/NoGo-Receptor seems like an optimal target for therapeutic reduction of ataxin-2 because 
in addition to gene-based strategies there are several ways in which it may be targeted, including receptor inhibition - demonstrated here — as well as neutralization of its ligands (Schwab, 2010). A RTN4/NoGo-Receptor Decoy (Wang et al., 2011, Wang et al., 2020) is being investigated in a clinical trial for chronic spinal cord injury (ClinicalTrials.gov identifier: NCT03989440). With additional targets and strategies to lower ataxin-2 levels in hand, combination therapies can be envisioned to have maximum therapeutic benefit and to mitigate potential negative effects of relying on a single target.

\section{Limitations of the study}

The effectiveness of RTN4R knockdown in rescuing degeneration in a mouse model of ALS remains to be tested. However, reducing ATXN2 is a validated method for rescuing degeneration phenotypes in a mouse model of TDP-43 toxicity and motor neuron degeneration (Becker et al., 2017) and in a mouse model of SCA2 (Scoles et al., 2017). Moreover, human genetics has provided compelling validation for ATXN2 as a therapeutic target for both ALS and SCA2 (Elden et al., 2010; Scoles and Pulst, 2018). Future work will be needed to determine the precise method for reducing $R T N 4 R$ - and subsequently $A T X N 2$ - in mouse models to test its influence on disease phenotypes. But given that clinical trials are underway to test a NoGo-Receptor inhibitor in spinal cord injury (ClinicalTrials.gov identifier: NCT03989440), lessons learned from that trial will hopefully aid in testing this approach for ALS and SCA2.

\section{Methods}

\section{Cell culture and transfection}

HEK293T cells were maintained in a $37^{\circ} \mathrm{C}$ incubator with $5 \% \mathrm{CO}_{2}$ in DMEM with Glutamax and HEPES (Thermo Fisher Scientific, cat\# 10564-029), 10\% fetal bovine serum (vol/vol; Invitrogen, cat\# 16000-044), and 1\% Pen/Strep (vol/vol; Invitrogen, cat\# 15140-122). Cells were reverse transfected on 96-well plates for luciferase assays. $25 \mu \mathrm{L}$ of Opti-MEM (Life Technologies, cat\# 31985-062) with $0.12 \mu \mathrm{L}$ of Dharmafect 1 (Horizon Discovery, cat\# T-2001-03) and 200nM (unless specified in figure) of ON-TARGETplus siRNA (Horizon Discovery) or non-targeting (Horizon Discovery, cat\# D-001810-10) was added to an individual well and incubated at room temperature for 30 minutes. $1.0 \times 10^{4}$ cells/well in $100 \mu \mathrm{L}$ of medium (without Pen/Strep) was added to the wells, and the plate was placed in the incubator for $72 \mathrm{hr}$. To interrogate proteasome or 
autophagy regulation by $\mathrm{HiBiT}$ assay, $72 \mathrm{hr}$ after reverse transfection cells were treated for $6 \mathrm{hr}$

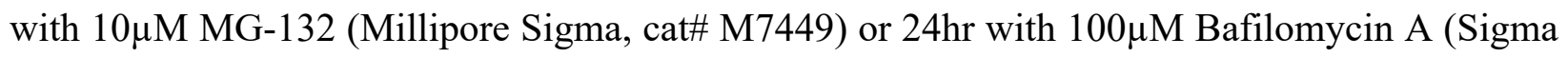
Aldrich, cat\# B1793) or DMSO prior to lysing.

For immunoblotting, unedited HEK293T cells were maintained as above. Unedited cells were used to reduce cell line-specific effects. Cells were reverse transfected on 12 -well plates. $200 \mu \mathrm{L}$ of OptiMEM with $4 \mu \mathrm{L}$ of Dharmafect 1 and 200nM of ON-TARGETplus siRNA or non-targeting control was added to an individual well and incubated at room temperature for 30 minutes. $2.0 \times 10^{5}$ cells/well were plated in $1 \mathrm{~mL}$ of medium without Pen/Strep and placed in the incubator for $72 \mathrm{hr}$ prior to lysing for experimentation.

\section{Small-scale Luciferase Assays}

Ataxin-2-HiBiT cells were lysed in-well with $125 \mu \mathrm{L}$ of Nano-Glo® HiBiT Lytic Buffer, and lysate from one well was split and used for detection of both HiBiT- and FFLuc-generated luminescence. $25 \mu \mathrm{L}$ of lysate was placed in two wells of an opaque white, flat bottom 96-well assay plate (Sigma Aldrich, cat\# CLS3990). For HiBiT detection, 25 $\mu \mathrm{L}$ of HiBiT lytic reagent (1:25 substrate, 1:50 LgBiT) was added to the lysate (Promega, cat\# N3050). For FFluc detection, $25 \mu \mathrm{L}$ of ONE-Glo Assay Buffer (Promega, cat\# E6120) was added to the lysate. Plates were incubated in the dark with gentle rotation for 10 minutes, then luminescence was measured on a Tecan Spark plate reader (Tecan). For all assays, HiBiT signal was normalized to the FFluc signal for each individual well of the original transfected plate then normalized to the non-targeting/untreated control, this value is represented in bar graphs.

\section{Genome Editing}

HEK293T cells (ATCC) were transfected using Lipofectamine ${ }^{\mathrm{TM}}$ CRISPRMAX $^{\mathrm{TM}}$ Cas9 Transfection Reagent (Thermo Fisher Scientific, cat\# cmax00003), TrueCut Cas9 Protein V2 (Thermo Fisher Technology, cat\# A36497), purified sgRNA and ssDNA (IDT). Sequences are listed in Table 1. 72hr later, cells were lifted and re-plated at a density of $<1$ cell/well in a 96-well plate. Wells were grown to confluency and split onto an additional plate. A HiBiT assay was performed on the additional plate as a preliminary screen for successful knock-in. The wells with HiBiT signal above the negative control (unedited cells) were maintained and confirmed for 
knock-in by Sanger sequencing (see Table 1 for primers). For firefly luciferase integration, the successful clone was transduced with lentivirus using pLenti CMV V5-LUC Blast (Addgene, cat\# w567-1), followed by blasticidin selection. Transduced cells were pooled and saved for future experimentation.

\section{Immunoblotting}

Cells were lysed in RIPA buffer (Sigma Aldrich, cat\# R0278) supplemented with Complete mini protease inhibitor tablet (EMD Millipore, cat\# 11836170001) and clarified by centrifugation at $21,000 \mathrm{x} g$ for 15 minutes. Protein concentration was measured by BCA protein assay (Thermo Fisher Scientific, cat\# 23225). Lysates were diluted to equal protein concentration in $1 \mathrm{X}$ NuPAGE® LDS Sample Buffer (Life Technologies, cat\# NP0008). Lysates were boiled at $70^{\circ} \mathrm{C}$ for 10 minutes, then loaded on a NuPAGE® Novex ${ }^{\circledR} 4-12 \%$ Bis-Tris Protein gel (Life Technologies, cat\# NP0321). Protein was transferred onto a nitrocellulose membrane (Bio-Rad, cat\# 162-0115) at $4^{\circ} \mathrm{C}$ for $1 \mathrm{hr}$ and 45 minutes in $1 \mathrm{X}$ NuPAGE ${ }^{\circledR}$ Transfer Buffer (Life Technologies, cat\# NP0006-1). Blocking and antibody incubation was performed in 2\% BSA (Sigma Aldrich, cat\# A7906) in PBS + 0.1\% tween-20 (PBST). Washes were performed in PSBT. Primary antibodies were used at 1:1000, this includes: ataxin-2 antibody (Novus, cat\# NBP190063), Tuj1 antibody (BioLegend, cat\# 802001), actin antibody (EMD Millipore, cat\# MAB1501), RTN4/NoGo-Receptor antibody (Abcam, ab184556), and GAPDH antibody (Sigma Aldrich, cat\# G8795). Goat anti-Rabbit HRP (Life Technologies, cat\# 31462) or goat anti-mouse HRP (Thermo Fisher Scientific, cat\# 62-6520) secondary antibodies were used at 1:5000. Membranes were developed in ECL Prime (Sigma Aldrich, cat\# GERPN2232), and imaged on a Bio-Rad ChemiDoc XRS+ imager (BioRad). HiBiT-based immunoblotting was performed according to the Nano-Glo® HiBiT Blotting System protocol (Promega, cat\# n2410).

For mouse cortex, male and female mice at P20 were sacrificed for tissue harvesting. Ice cold RIPA buffer with protease inhibitor was added and tissue was homogenized using a motorized pestle. Crude lysates were rocked at $4^{\circ} \mathrm{C}$ for 30 minutes, passed through a homogenization column (Qiagen, cat\# 79656), and centrifuged at 21,000 x $g$ for 15 minutes. Protein was quantified in the clarified supernatant and prepared for immunoblotting as above. 


\section{Whole-genome siRNA screen}

The whole-genome siRNA screen was performed in the High-Throughput Bioscience Center (HTBC) at Stanford University. Briefly, we used the Dharmacon Human Genome siARRAY library (cat\# G-005000-025) to target 21,121 genes individually in a single well of a 384-well plate with 4 pooled siRNAs. All siRNA pools were tested in duplicate for both FFluc and HiBiT on 4 separate plates. Each plate had three controls: siTOX control siRNA, nontargeting control siRNA, and ATXN2 siRNA (Horizon Discovery, cat\# L-011772-00) as a toxicity, negative, and positive control, respectively. All siRNAs were reverse transfected using $10 \mu \mathrm{L}$ of Opti-MEM, $0.075 \mu \mathrm{L} /$ well of Dharmafect 1 , and $10 \mu \mathrm{L}$ siRNA (final concentration of $50 \mathrm{nM}$ ). Cells were seeded at 1000 cells/well in $30 \mu \mathrm{L}$ of media (as above without Pen/Strep) in solid white 384-well plates, then placed in a $37^{\circ} \mathrm{C}$ incubator with $5 \% \mathrm{CO}_{2}$. After 3 days, plates were removed from the incubator. HiBiT lytic reagent was made by diluting Nano-Glo® HiBiT Lytic Substrate (1:50) and LgBiT Protein (1:100) in Nano-Glo® HiBiT Lytic Buffer. For HiBiT detection, $10 \mu \mathrm{L}$ of HiBiT lytic reagent was dispensed into wells with a Multidrop Reagent Dispenser (Thermo Scientific), and rapidly shook for 15 seconds. For FFluc detection, $10 \mu \mathrm{L}$ of ONE-Glo Assay Buffer was dispensed into wells and rapidly shook for 15 seconds. Luminescence was read on a Tecan Infinite M1000 Pro (Tecan).

Z-scores were calculated for each siRNA replicate using the in-plate standard deviation, then averaged for both HiBiT and FFluc conditions respectively. The average Z-scores were used to filter for primary screen hits. siRNAs were only considered if they had an average FFluc Z-score greater than -1. siRNAs were categorized as negative regulators of ataxin-2 expression if they had an average HiBiT Z-score less than -1.65. 102 of these were retested in a secondary screen by handpicking siRNAs from the original library stock. The same experimental parameters applied, except for the performance of a single replicate for FFluc detection. High confidence hits were chosen if they had a greater than $30 \%$ decrease in average HiBiT levels relative to the non-targeting siRNA control run in parallel on the same plate. High confidence hits were ranked by average HiBiT Z-score, then were filtered further to determine the most optimal therapeutic target. These were filtered out if they had an average gene effect less than -1 as determined by DEMETR2 or CERES (depmap.org) or GTEx cortical pTPM less than 15 (proteinatlas.org). 


\section{RNA Quantification}

Cells were reverse transfected with siRNA in 12-well plates as described above. RNA was isolated using the PureLink ${ }^{\circledR}$ RNA Mini Kit according to the kit protocol with DNase digestion (Thermo Fisher Scientific, cat\# 12183025). 500ng of RNA was used to make cDNA using the Applied Biosystems High-Capacity cDNA Reverse Transcription kit (Thermo Fisher Scientific, cat\# 4368813). qPCR was performed in a $20 \mu \mathrm{L}$ reaction using TaqMan ${ }^{\mathrm{TM}}$ Universal Master Mix II (Thermo Fisher Scientific, cat\# 4440040) and 25ng of RNA. $1 \mu \mathrm{L}$ of $20 \mathrm{X}$ TaqMan gene-specific expression assay was added to the reaction (Thermo Fisher Scientific; human ATXN2: Hs00268077_m1, human ACTB: Hs01060665_g1, human RTN4R: Hs00368533_m1, mouse ATXN2: Mm00485932_m1, mouse GAPDH: Mm99999915_g1, mouse RTN4R: Mm00452228_m1). All conditions were run in technical triplicates that were averaged to account for each of the biological triplicates. Thermocycler was programmed according to the suggested protocol. Relative expression was calculated using the $\Delta \Delta \mathrm{Ct}$ method.

\section{Lentivirus production}

HEK293T cells were grown on $10 \mathrm{~cm}$ culture dishes to $80-90 \%$ confluency. Cells were transfected

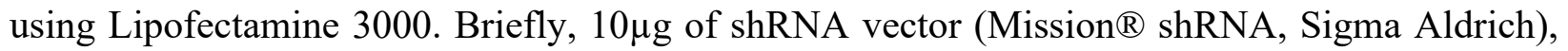

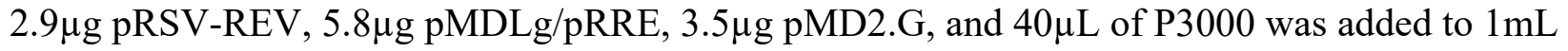
of Opti-MEM. This was combined with another $1 \mathrm{~mL}$ of Opti-MEM with $40 \mu \mathrm{L}$ of Lipofectamine 3000. This mixture was incubated at room temperature for 10 minutes then added to cells in media without antibiotics. $48 \mathrm{hr}$ after transfection, media was removed from cells, passed through a $0.45 \mu \mathrm{m}$ PES filter, and combined with Lenti-X concentrator (Takara, cat\# 631232). The mixture was incubated over night at $4^{\circ} \mathrm{C}$. This was centrifuged at $1,500 \times \mathrm{g}$ for 45 minutes at $4^{\circ} \mathrm{C}$. The pellet was resuspended in 1mL Neurobasal Medium (Life Technologies, cat \# 21103-049), 50 $\mu \mathrm{L}$ was added directly to cells for transduction.

\section{Primary neuron culture}

Animals were bred, cared for, and experimented on as approved by the Administrative Panel of Laboratory Animal Care (APLAC) of Stanford University. Time-pregnant C57BL/6 mice were procured from Charles River Labs. Mouse embryos were removed at E16.5, and cortices were isolated and placed in ice cold Dissociation Media (DM; PBS without $\mathrm{Mg}^{2+}$ or $^{2{ }^{2+}}$, supplemented 
with $0.6 \%$ glucose, $10 \mathrm{mM}$ HEPES, and Pen/Strep). Neurons were dissociated with the Papain Dissociation System (Worthington Biochemical Corporation, cat\# LK003153). Cells were seeded on Poly-L-lysine (Sigma Aldrich, cat\# P4832) coated 24-well plates at a density of 350,000cells/well. They were grown in Neurobasal media supplemented with B-27 at 1:50 (Life Technologies, cat\# 17504-044), Glutamax at 1:100 (Invitrogen, cat\# 35050-061) and Pen/Strep. Neurons were maintained in a $37^{\circ} \mathrm{C}$ incubator with $5 \% \mathrm{CO}_{2}$ with half media changes every 4 to 5 days.

At DIV 5, neurons were transduced with virus as above (Mission ${ }^{\circledR} \operatorname{shRNA}$, mouse RTN4R: TRCN0000436683). 24hr later, a half media change was performed. Neurons were maintained for 12 days after transduction prior to harvesting for experimentation. For NEP1-40 (Tocris, cat\# 1984) treatment, $1 \mathrm{mg}$ of NEP1-40 was diluted in $21.62 \mu \mathrm{L}$ of DMSO and $843.2 \mu \mathrm{L}$ of nuclease-free water (Thermo Fisher Scientific, cat\# AM9937) to a working concentration of $250 \mu \mathrm{M}$. The peptide was added to the final concentration specified along with vehicle $(0 \mu \mathrm{M})$. Cells were maintained for $48 \mathrm{hr}$ prior to experimentation.

For microfluidics chamber experiments, primary neurons were isolated as above and plated on one side of a Poly-D-lysine coated microfluidics chamber (Xona Microfluidics, cat\# XC450) with a microchannel length of $450 \mu \mathrm{m}$ at a density of 200,000cells/chamber. Media was changed the next day, then half-changed every 3 days following. Lentivirus was added to the somatic compartment as above, then maintained for 12 days prior to axotomy. Vacuum-assisted axotomy was achieved by complete aspiration of media from the axonal compartment/inner chamber, allowing for an air bubble to dislodge and shear axons(Tong et al., 2015). Media was replaced and completely aspirated a second time. Media was replaced carefully to prevent the inclusion of any air bubbles in the inner chamber. A half media change was performed the next day. Neurons were allowed to regrow axons for a total of $48 \mathrm{hr}$ prior to fixation.

\section{iNeuron culture}

We induced neuron differentiation in human iPSC-derived neurons (iNeurons) using a previously established protocol with a Tet-On induction system that allows expression of the transcription factor NGN2(Bieri et al., 2019). Briefly, iPS cells were maintained with mTeSR1 medium 
(Stemcell Technologies, cat\# 85850) on Matrigel (Fisher Scientific, cat\# CB-40230). On the next day of passage, NGN2 was expressed by adding doxycycline $(2 \mu \mathrm{g} / \mathrm{ml})$ and selection with puromycin $(2 \mu \mathrm{g} / \mathrm{ml})$ for rapid and highly efficient iNeuron induction. Three days after induction, iNeurons were dissociated and grown in Neurobasal medium containing N-2 supplement (Gibco, cat\# 17502048), B-27 supplement, BDNF (R\&D Systems) and GDNF (R\&D Systems) on Matrigel-coated plates.

At 7 days post neural induction, iNeurons were transduced with virus as above (Mission ${ }^{\circledR}$ shRNA, human RTN4R: TRCN0000061558). 24hr later, a half media change was performed. iNeurons were maintained for 3 days before being re-transduced with a half dose of virus, then maintained for another 5 days prior to harvesting for experimentation. For NEP1-40 treatment, 1mg of NEP140 was diluted as above. The peptide was added at 7 days post induction to the final concentration specified along with vehicle $(0 \mu \mathrm{M})$. Cells were maintained for $48 \mathrm{hr}$ prior to lysis.

\section{Immunocytochemistry and fluorescence microscopy}

Cells were fixed for 10 minutes in a solution of 4\% paraformaldehyde/4\% sucrose in PBS-MC (PBS with $1 \mathrm{mM} \mathrm{MgCl}_{2}$ and $0.1 \mathrm{mM} \mathrm{CaCl}_{2}$ ). Then cells were washed in PBS-MC, and permeabilized for 10 minutes in $0.1 \%$ Triton-X in PBS-MC. Cells were blocked in 2\% BSA for an hour, then incubated in primary antibody for at least 2 hours at room temperature [ataxin-2 (Novus), MAP2 (Synaptic Systems, cat\# 188004), Tuj1 (BioLegend, cat\# 802001), NeuN (EMD Millipore, cat\# MAB377)]. Cells were washed 3 times with PBS-MC, followed by incubation in species-specific Alexa Fluor ${ }^{\circledR}-$ labeled secondary antibody (Thermo Fisher Scientific) for 1 hour at 1:1000. Cells were subsequently washed and placed in ProLong Gold Antifade with DAPI (Thermo Fisher Scientific, cat\# P36931), and imaged using a Leica DMI6000B fluorescent microscope.

Images were processed in ImageJ. For neuronal expression, individual MAP2 labeled soma were selected as regions of interest (ROIs), in which ataxin-2 fluorescence was measured and averaged within each frame. This was performed for 4 frames per biological replicate (4 replicates for the NEP1-40 treatment and 3 for the vehicle), totaling 16 frames for the NEP1-40 condition and 12 for the vehicle. For stress granule analysis, stress granules were automatically determined based 
on shape and size using the Analyze Particles function in ImageJ in the G3BP channel. Each stress granule was made into an ROI in which TDP-43 fluorescence was measured and averaged for every stress granule in the frame. This was performed for 6 frames per biological duplicate, totaling 12 frames per condition. For axonal regrowth after axotomy, entire axonal compartments were imaged for three microfluidics chambers per shRNA condition ( 9 total). A grid was superimposed onto each image with demarcations every $15 \mu \mathrm{m}$ after the end of the microchannels. The length of every Tuj1-labeled neurite with a growth cone was determined by their crossing point on the grid and binned into lengths. The average of all neurites from each condition was taken.

\section{Statistical analyses}

Statistical analyses were performed in GraphPad Prism v.9, except the screen data calculations, which was performed in MATLAB (MathWorks). An unpaired Student's t-test (two tailed) with a 95\% confidence interval (CI) was performed for all assays comparing two experimental groups. A two-way analysis of variance (ANOVA) with a 95\% CI was performed for the HiBiT assays with multiple siRNA conditions compared to respective non-targeting controls run in parallel and siRNA/drug treatment. A one-way ANOVA with multiple comparisons was performed for all other experiments with more than two experimental conditions. A Fisher's LSD test was performed for the NEP1-40 treated HiBiT assay. A Dunnett's multiple comparisons test was performed for all others. All bar graphs show the mean \pm SEM. All samples were randomly assigned to experimental groups. No statistical methods were used to predetermine sample sizes.

Table 1:

\begin{tabular}{|c|c|}
\hline & Sequence \\
\hline $\begin{array}{l}\text { Target-specific sgRNA } \\
\text { sequence }\end{array}$ & AGCCTTACAACTGCTGTTGG \\
\hline HDR ssDNA & $\begin{array}{l}\text { GCTTGGCTAATATTTGGGGAGGGGGTTTGTTAAGGCCTTTT } \\
\text { TTTCTACCCCATGAACAAGTCTTCTGGGAGTTTTATCTGAAG } \\
\text { TGGTTTTACGTCTGACTGGTTTGTTTCTACCCACCCACCCAA } \\
\text { CCCTCCCCACTTTGGTGCAGATGGGAGGGGGAAAAGCGAA } \\
\text { TTCAATTTTGAGTTTTGTTCAGCTAGCACGAGGATAGTTTAC } \\
\text { AATCATGTGCTGCAGAGACACTAGGCTGATGTGTGGTGTTG } \\
\text { CCAGTTTTCTGTTTCAATGTTCGCTTTTCTTTTTACAGTACAA }\end{array}$ \\
\hline
\end{tabular}




\begin{tabular}{|c|c|}
\hline & $\begin{array}{l}\text { GCCCACCACGTGAGCGGCTGGCGGCTGTTCAAGAAGATTA } \\
\text { GCTAAGGCTGCCCTGGAGGAACCGAAAGGCCAAATTCCCTC } \\
\text { CTCCCTTCTACTGCTTCTACCAACTGGAAGCACAGAAAACTA } \\
\text { GAATTTCATTTATTTTGTTTTTAAAATATATATGTTGATTTCTT } \\
\text { GTAACATCCAATAGGAATGCTAACAGTTCACTTGCAGTGGAA } \\
\text { GATACTTGGACCGAGTAGAGGCATTTAGGAACTTGGGGGCT } \\
\text { ATTCCATAATTCCATATGCTGTTTCAGAGTCCCGCAGGTACC } \\
\text { CCAGCTCTGCTTGCCGAAACTGGAAGTTATTTATTTTTTAATA } \\
\text { ACCCTTG }\end{array}$ \\
\hline $\begin{array}{l}\text { Forward Primer for exon } 25 \\
\text { amplification and } \\
\text { sequencing }\end{array}$ & GCAATACTGGTGCTTGGCTAATATTTGGGG \\
\hline $\begin{array}{l}\text { Reverse Primer for exon } 25 \\
\text { amplification and } \\
\text { sequencing }\end{array}$ & CACTCTTGTTACTTCTTTTGCTAGCTGATGTG \\
\hline
\end{tabular}

\section{Figures and Legends:}


A

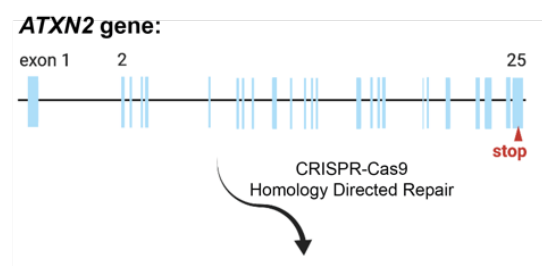

HiBiT knock-in sequence in HEK293T cell line*:

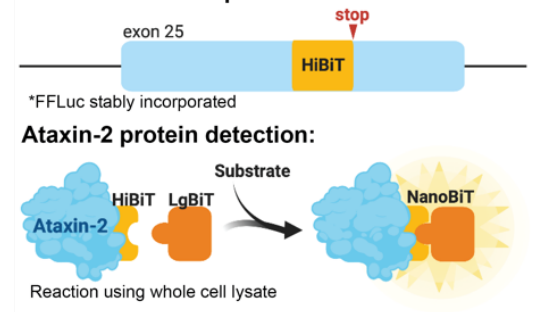

$\mathbf{F}$

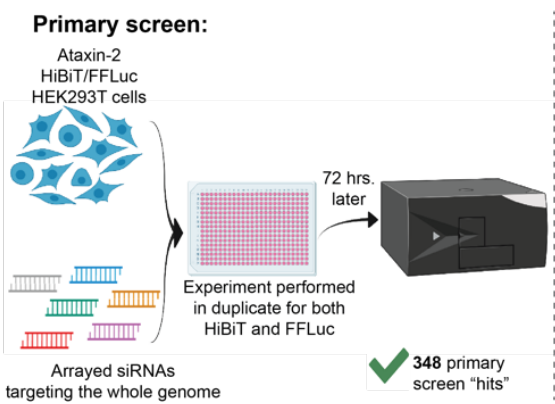

H

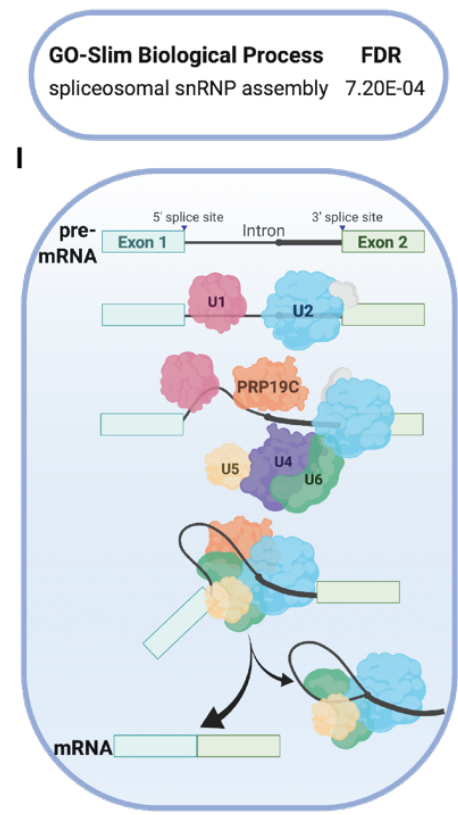

J
E

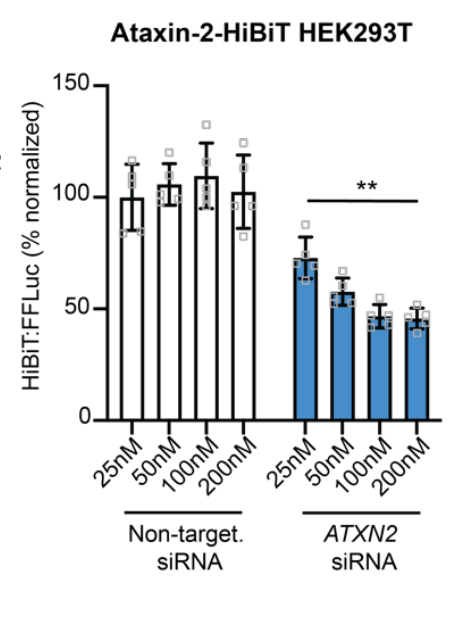

B

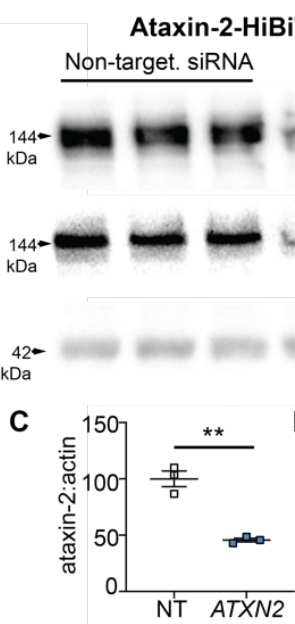

HEK293T

ATXN2 SiRNA

Secondary screen:

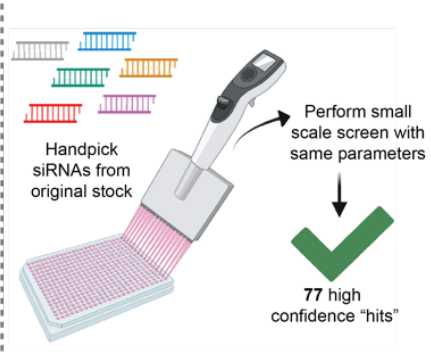

G

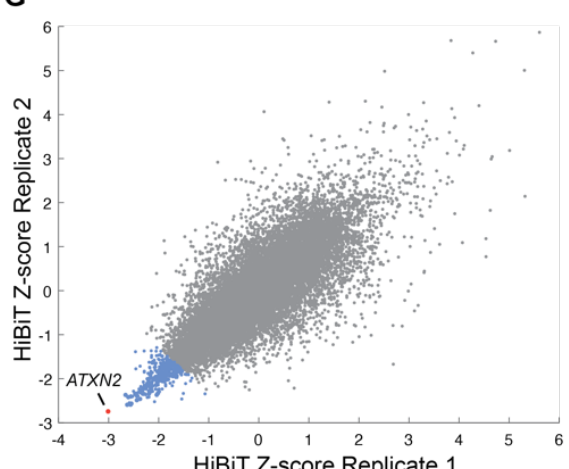

K

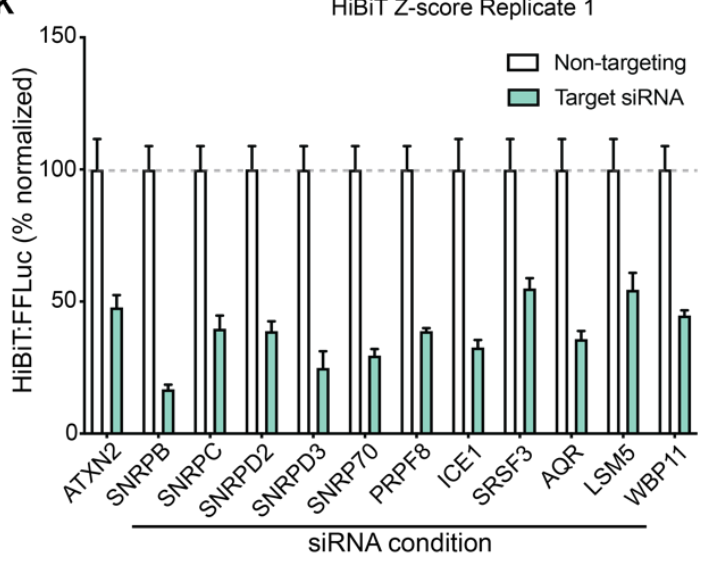

L

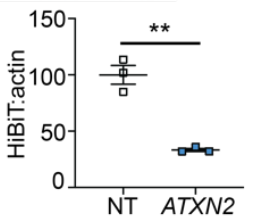

High-confidence hits: Sm/LSm spliceosome U1, U2, U4, U5 SNRPB 1 $\begin{array}{ll}\text { SNRPD2 } & \text { LSM4 } \\ \text { LSM5 }\end{array}$ SNRPD3$$
\text { u }
$$$$
\begin{array}{r}
\text { U1 } \\
\text { SNRPC } \\
\text { SNRP70 }
\end{array}
$$

U2
SNRPA1
U2AF1$$
\begin{aligned}
& \text { SF } 3 A 1 \\
& \text { SF3A2 }
\end{aligned}
$$$$
\begin{aligned}
& \text { SF3A3 } \\
& \text { SF3B2 }
\end{aligned}
$$$$
\text { SF3B6 }
$$

U4/U6 PRPF3

U5

PRPF6

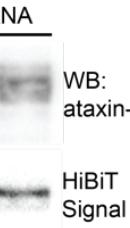

WB: 
form NanoBiT. As a control, we stably incorporated firefly luciferase (FFLuc) into this line. (B) Antibody-based immunoblotting and HiBiT substrate-based detection on ataxin-2-HiBiT cell lysates transfected with siRNA. Quantified in (C) and (D). (E) HiBiT signal measured via luciferase assay on cells transfected with increasing doses of siRNA. (F) Schematic of the wholegenome siRNA screen for regulators of ataxin-2 levels. (G) Plot showing results of HiBiT replicates after filtering for changes in FFLuc. Datapoints in blue are primary screen hits that decrease ataxin-2. ATXN2 siRNA (red) was the strongest hit. (H) GO-Slim Biological Process analysis of the hits from the primary screen. (I) Summary of the major steps in pre-mRNA splicing, illustrating the involvement of the PRP19-associated complex (PRP19C) and the U1, U2, U4, U5, and U6 snRNP RNA-protein complexes. (J) A list of the siRNAs that reduce ataxin-2 validated in the secondary screen. (K) Ataxin-2-HiBiT cells treated with siRNAs against several splicing components followed by a luciferase assay to measure HiBiT activity. Each splicing factor knockdown significantly reduces HiBiT signal relative to non-targeting. Two-way ANOVA with multiple comparisons: WBP11, SRSF3, and LSM5, $\mathrm{p} \leq 0.001$. ATXN2, SNRPB, SNRPC, SNRPD2, SNRPD3, SNRP70, PRPF8, ICE1, and $A Q R, \mathrm{p} \leq 0.0001$. (L) Immunoblot of unedited HEK293T cell lysates after siRNA treatment. C and D, Student's t-test. E, One-way ANOVA with multiple comparisons. $* * \mathrm{p} \leq 0.01$. Error bars represent \pm SEM. 


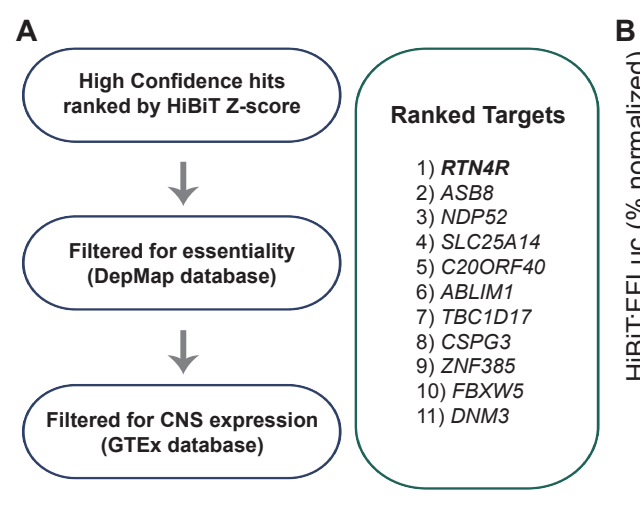

E

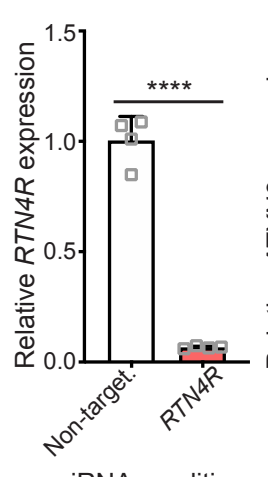

siRNA condition
$\mathbf{F}$

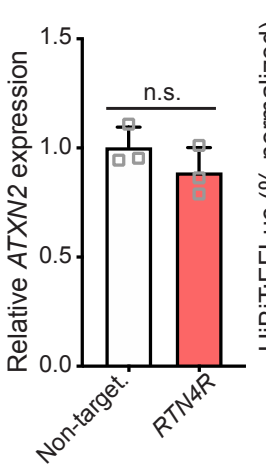

siRNA condition
B
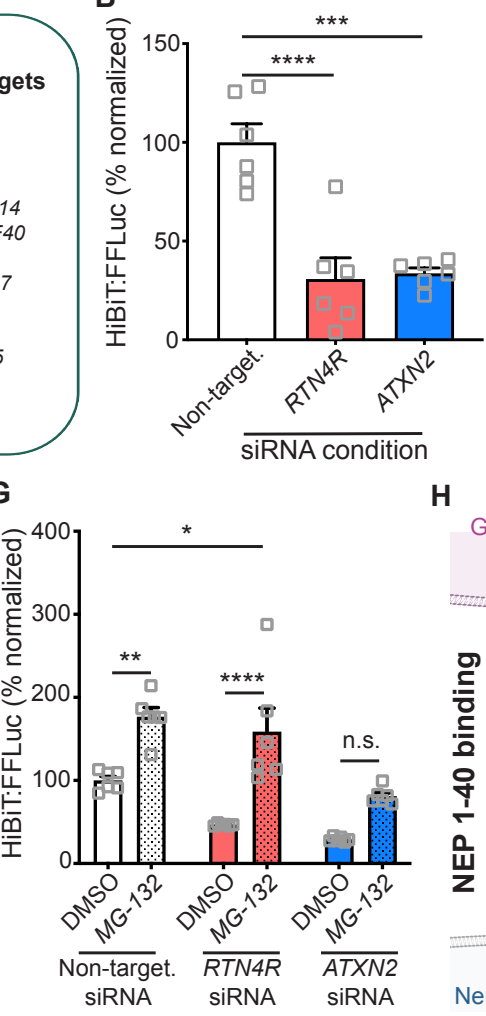

H
C
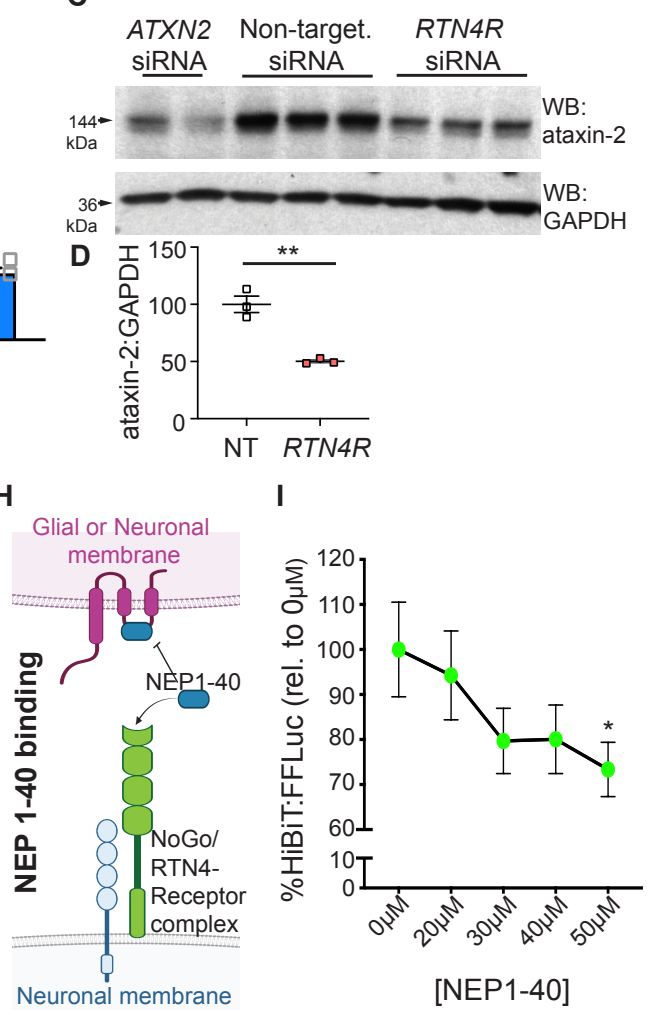

[NEP1-40]

Figure 2: Targeting $\boldsymbol{R} T N 4 \boldsymbol{R}$ lowers levels of ataxin-2. (A) High confidence hits ranked by average HiBiT Z-score, then filtered for essentiality (gene effect, DepMap) and CNS expression (GTEx). (B) HiBiT signal measured by luciferase assay in ataxin-2-HiBiT cells transfected with designated siRNA. (C) Immunoblot for ataxin-2 and GAPDH on lysates derived from unedited HEK293T cells treated with designated siRNA. Ataxin-2 levels are quantified in (D). We performed RT-qPCR on RNA from cells treated as in (C). We probed for RTN4R transcript (E) or $A T X N 2$ transcript (F) along with $A C T B$ for normalization. (G) We treated ataxin-2-HiBiT cells with siRNA then treated cells for 8hr with proteasome inhibitor MG-132 or DMSO and performed a luciferase assay to measure HiBiT activity. (H) The NEP1-40 peptide, a shared extracellular region of the NoGo proteins, binds to RTN4/NoGo-Receptor and prevents further signaling through the receptor. (I) We treated ataxin-2-HiBiT cells for $48 \mathrm{hr}$ with increasing doses of NEP140 and performed a luciferase assay to measure HiBiT activity. B and I, One-way ANOVA with multiple comparisons. G, Two-way ANOVA with multiple comparisons. D, E, and F, Student's ttest. $* \mathrm{p} \leq 0.05, * * \mathrm{p} \leq 0.01, * * * \mathrm{p} \leq 0.001, * * * * \mathrm{p} \leq 0.0001$. Error bars represent $\pm \mathrm{SEM}$. 
A
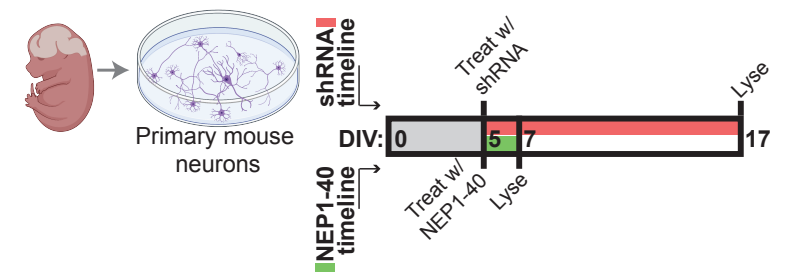

C

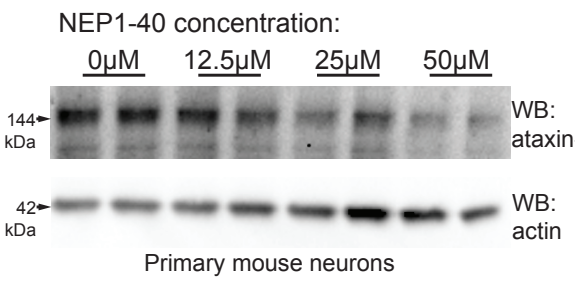

G

H
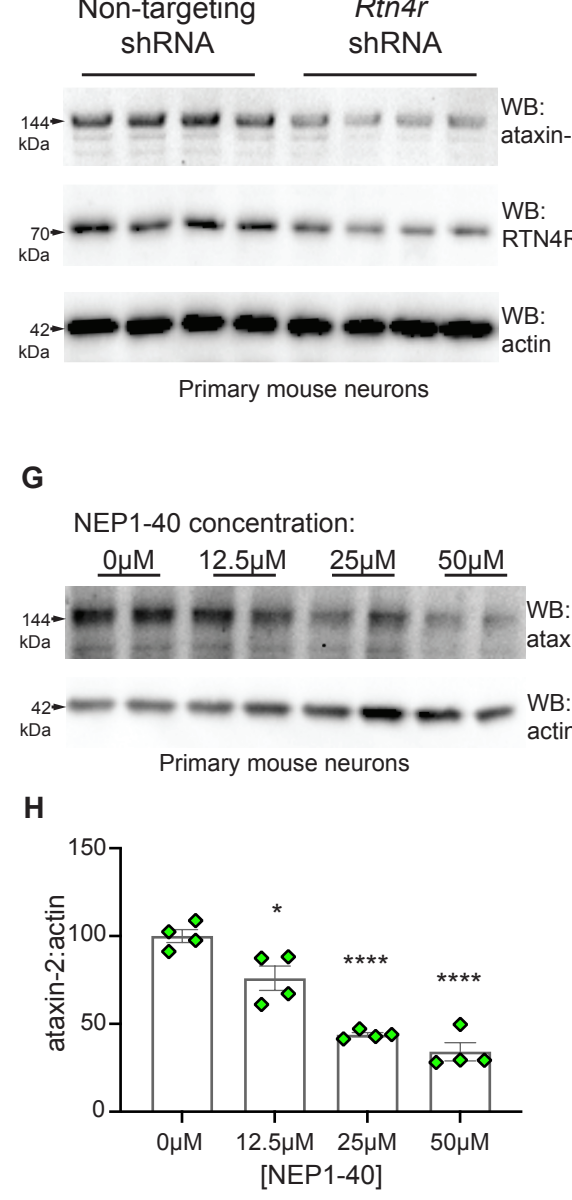

Primary mouse neurons

M

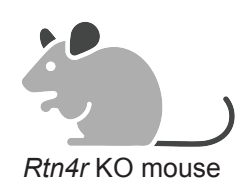

D

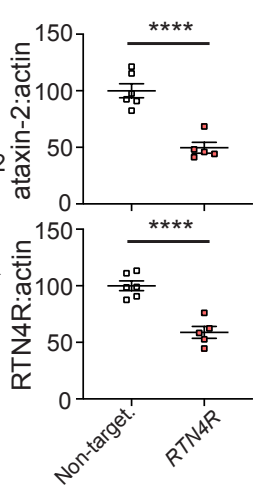

I

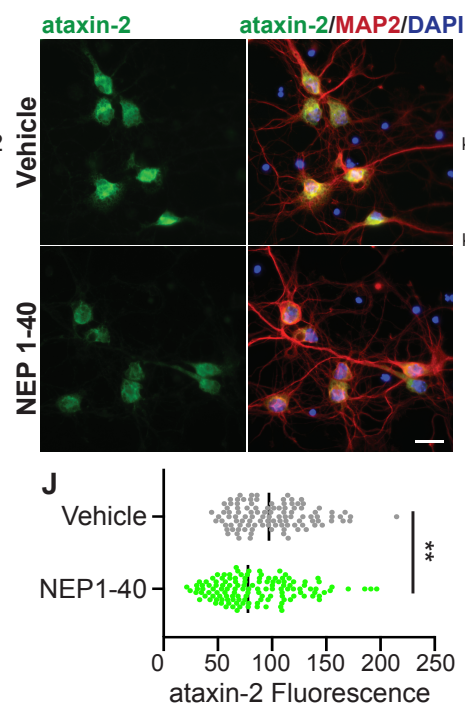

B

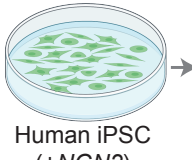

(+NGN2)

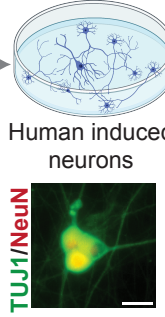

E

Non-targeting RTN4R shRNA

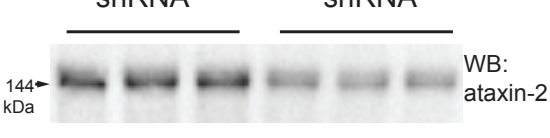

$\mathbf{F}$

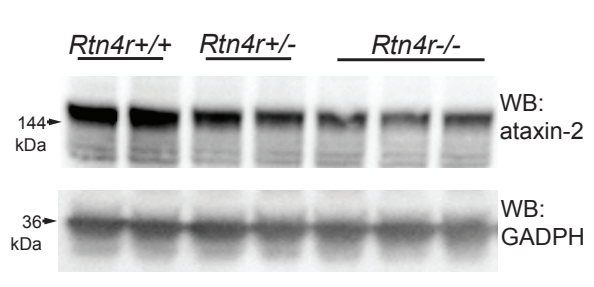

Cortex

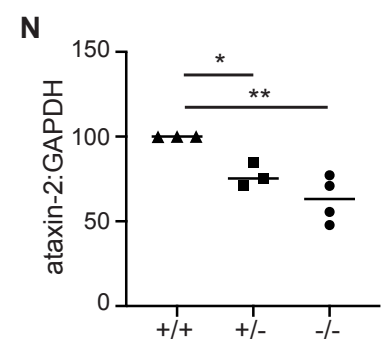

Figure 3: RTN4R knockdown or inhibition of RTN4/NoGo-Receptor in mouse and human neurons and in mouse brain reduces ataxin-2 levels. (A) Primary neurons isolated from embryonic mouse cortex. Treatment timeline for shRNA lentivirus or RTN4/NoGo-Receptor 
peptide inhibitor NEP1-40 in primary mouse neurons. DIV=days in vitro. (B) Induced neuron differentiation in a human iPSC line with NGN2 stably integrated, as verified by Tuj1 (green) and NeuN (red) immunostaining, scale bar $20 \mu \mathrm{m}$. Treatment timeline for shRNA lentivirus or NEP140 in human induced neurons (iNeurons). DPI=days post induction. (C) Immunoblot on lysates from mouse neurons treated with shRNA. (D) Quantification of ataxin-2 and RTN4/NoGoReceptor levels. (E) Immunoblot on lysates from iNeurons treated with shRNA. (F) Quantification of ataxin-2 and RTN4/NoGo-Receptor. (G) Immunoblot on lysates from primary mouse neurons treated with increasing doses of NEP1-40. Quantification is shown in (H). (I) Immunocytochemistry and fluorescence microscopy on mouse neurons treated with $50 \mu \mathrm{M}$ NEP140. MAP2 labels neurons, DAPI labels nuclei. Scale bar $=20 \mu \mathrm{m}$. (J) Quantification of neuronal ataxin-2 fluorescence. (K) Immunoblot on lysates from iNeurons treated for 48 hours with increasing doses of NEP1-40. Quantification is shown in (L). (M) Immunoblot on whole cortex lysates from $R T N R+/+,+/-$, and -/- mice. Quantification in (N). D, F, and J, Student's t-test. H, L, and N, One-way ANOVA with multiple comparisons. ${ }^{*} \mathrm{p} \leq 0.05, * * \mathrm{p} \leq 0.01, * * * \mathrm{p} \leq 0.001, * * * * \mathrm{p}$ $\leq 0.0001$. Error bars represent \pm SEM. 
A

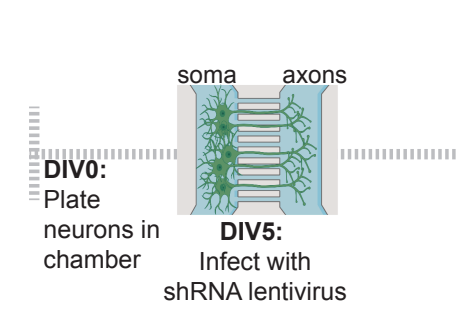

C

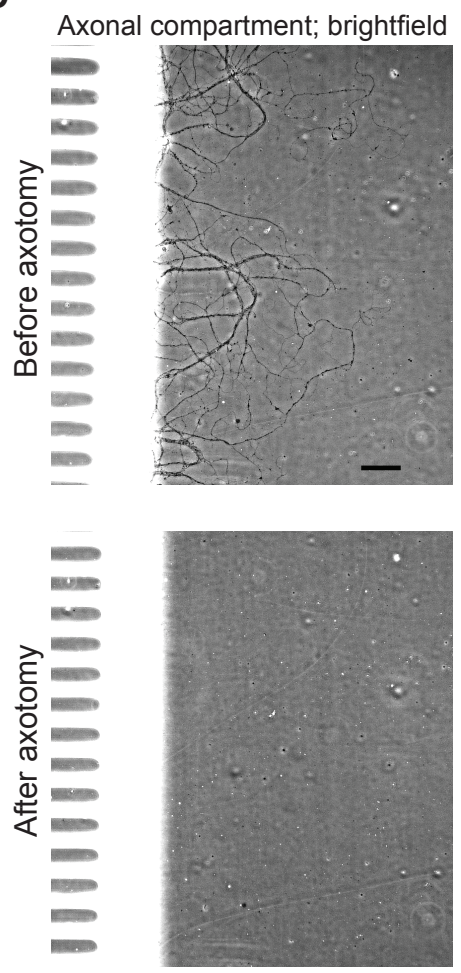

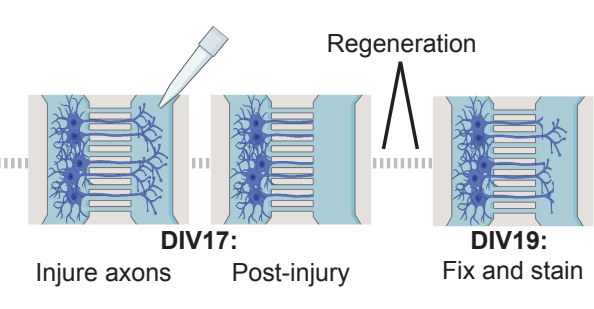

D

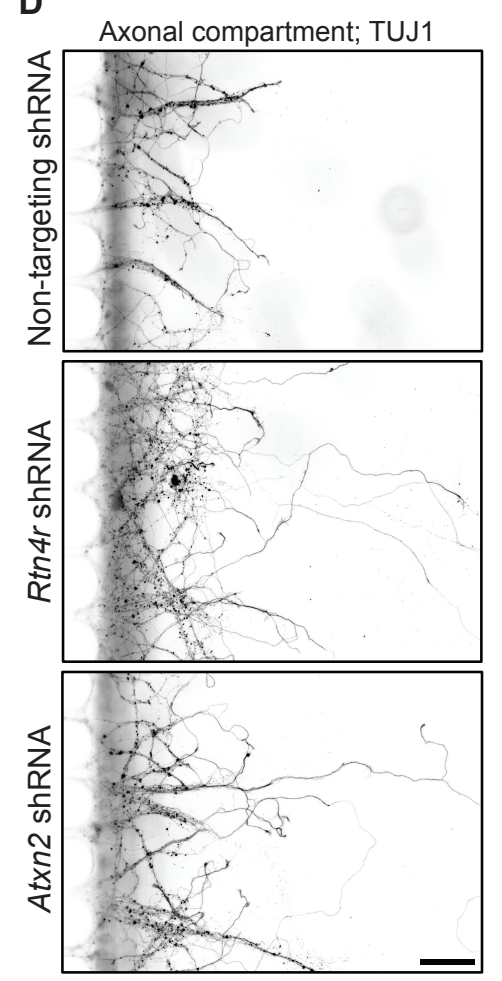

B

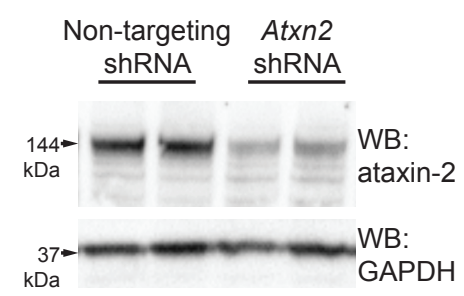

E

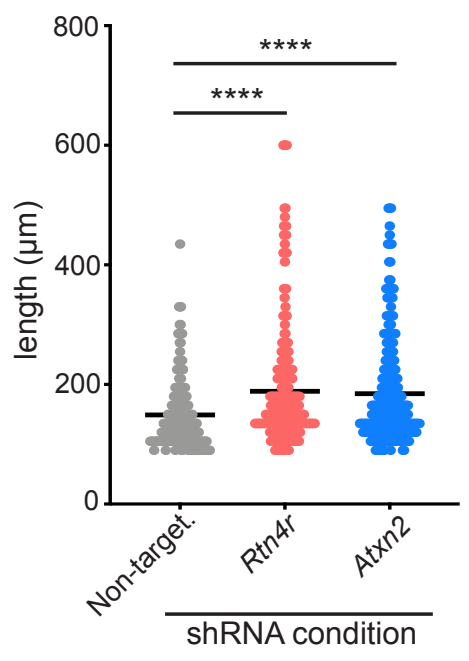

Figure 4: Reduction of ataxin-2 increases axonal regrowth after axotomy. (A) Timeline for axotomy and regeneration experiment using mouse primary neurons grown in microfluidics chambers. (B) Immunoblot on lysates from mouse neurons treated with Atxn2 shRNA. (C) Brightfield images of an inner chamber of the axonal compartment of a microfluidics chamber before and after vacuum-assisted axotomy. Scale bar $=50 \mu \mathrm{m}$. (D) Immunocytochemistry and fluorescence microscopy on the axonal compartment after 48 hours of regrowth after axotomy. Tuj1 labels axons. Scale bar $=50 \mu \mathrm{m}$. (E) Quantification of the length of regenerating neurites (identified by the morphological presence of a growth cone) from three separate chambers per condition. One-way ANOVA with multiple comparisons. $* * * * \mathrm{p} \leq 0.0001$. Error bars represent \pm SEM. 


\section{Supplemental information:}

\section{Table S1:}

\begin{tabular}{|c|c|c|c|c|}
\hline siRNA target & GenelD & $\begin{array}{c}\% \text { HiBiT signal relative to } \\
\text { control }\end{array}$ & Category & Further Details \\
\hline ATXN2 & NM_002973 & 14.74 & LSM protein & Ataxin-2 \\
\hline SNRPD3 & NM_004175 & 17.79 & splicing & Sm/LSm spliceosome \\
\hline NDE1 & NM_017668 & 18.00 & neuronal function & involved in neurodevelopment \\
\hline SNRPB & NM_003091 & 19.16 & splicing & Sm/LSm spliceosome \\
\hline P14 & NM_016047 & 19.77 & splicing & U2 spliceosome, SF3B6 \\
\hline PRPF8 & NM_006445 & 21.46 & splicing & U5 spliceosome \\
\hline SFPQ & NM_005066 & 21.87 & splicing & Integral spliceosome component \\
\hline KIAA0947 & XM_029101 & 22.13 & splicing & Associated spliceosome component \\
\hline SFRS3 & NM_003017 & 22.38 & splicing & Integral spliceosome component \\
\hline AQR & NM_014691 & 23.47 & splicing & PRP19 complex \\
\hline SF3A1 & NM_005877 & 23.78 & splicing & U2 spliceosome \\
\hline MFAP1 & NM_005926 & 23.80 & splicing & Integral spliceosome component \\
\hline SNRPD2 & NM_004597 & 24.26 & splicing & Sm/LSm spliceosome \\
\hline SF3A3 & NM_006802 & 24.63 & splicing & U2 spliceosome \\
\hline XАB2 & NM_020196 & 25.74 & splicing & PRP19 complex \\
\hline KIAA1160 & NM_020701 & 26.74 & splicing & PRP19 complex \\
\hline WBP11 & NM_016312 & 27.22 & splicing & Associated spliceosome component \\
\hline SF3B2 & XM_290506 & 27.48 & splicing & U2 spliceosome \\
\hline SART1 & NM_005146 & 27.80 & miscellaneous & \\
\hline SF3B4 & NM_005850 & 28.66 & splicing & U2 spliceosome \\
\hline SNRPC & NM_003093 & 28.78 & splicing & U1 spliceosome \\
\hline SNRPA1 & NM_003090 & 29.41 & splicing & U2 spliceosome \\
\hline CRNKL1 & NM_016652 & 29.50 & splicing & Associated spliceosome component \\
\hline SNRP70 & NM_003089 & 31.07 & splicing & U1 spliceosome \\
\hline FLJ30656 & NM_152344 & 31.61 & LSM protein & $\begin{array}{l}\text { shared protein domain with Ataxin-2 } \\
\text { and known Ataxin-2 interactor }\end{array}$ \\
\hline ANKRD23 & NM_144994 & 32.19 & miscellaneous & \\
\hline U5-116KD & NM_004247 & 32.47 & splicing & U5 spliceosome \\
\hline SNRPE & NM_003094 & 33.74 & splicing & Sm/LSm spliceosome \\
\hline TRAPPC1 & NM_021210 & 34.60 & autophagy & $\begin{array}{l}\text { TRAPP complex involved in } \\
\text { autophagy, protein trafficking, stress } \\
\text { granule formation }\end{array}$ \\
\hline HNRPC & NM_004500 & 34.85 & splicing & Associated spliceosome component \\
\hline MGC29784 & NM_173659 & 35.06 & mitochondria & $\begin{array}{l}\text { oxidative stress, pseudouridylation, } \\
\text { RPUSD3 }\end{array}$ \\
\hline DJ467N11.1 & NM_022091 & 35.06 & splicing & $\begin{array}{l}\text { Integral spliceosome component, } \\
\text { ASCC3 }\end{array}$ \\
\hline FLJ14936 & NM_032864 & 35.43 & splicing & $\begin{array}{l}\text { Integral spliceosome component, } \\
\text { PRPF38A }\end{array}$ \\
\hline FLJ30668 & NM_153015 & 35.75 & autophagy & TMEM74 \\
\hline
\end{tabular}


bioRxiv preprint doi: https://doi.org/10.1101/2021.12.20.473562; this version posted December 21,2021 . The copyright holder for this preprint (which was not certified by peer review) is the author/funder, who has granted bioRxiv a license to display the preprint in perpetuity. It is made available under aCC-BY-NC 4.0 International license.

\begin{tabular}{|c|c|c|c|c|}
\hline U2AF1 & NM_006758 & 36.03 & splicing & U2 spliceosome \\
\hline SNRPD1 & NM_006938 & 36.66 & splicing & Sm/LSm spliceosome \\
\hline MGC10433 & NM_024321 & 37.00 & miscellaneous & RNA binding, RBM42 \\
\hline IK & NM_006083 & 37.44 & miscellaneous & RNA binding \\
\hline SLU7 & NM_006425 & 38.71 & splicing & Integral spliceosome component \\
\hline IBRDC2 & NM_182757 & 38.81 & proteasome & E3 ligase \\
\hline PRPF3 & NM_004698 & 39.43 & splicing & U4/U6 spliceosome \\
\hline FLJ31196 & NM_152908 & 40.30 & miscellaneous & SLC47A2 \\
\hline LSM2 & NM_021177 & 41.34 & splicing & Sm/LSm spliceosome \\
\hline SF3A2 & NM_007165 & 43.50 & splicing & U2 spliceosome \\
\hline C10ORF77 & NM_024789 & 43.65 & miscellaneous & MFSD13A \\
\hline NDP52 & NM_005831 & 43.86 & autophagy & $\begin{array}{l}\text { Interacts with TBK1, cargo receptor } \\
\text { that recruits ULK1 }\end{array}$ \\
\hline LSM5 & NM_012322 & 43.86 & splicing & Sm/LSm spliceosome \\
\hline TBC1D17 & NM_024682 & 44.65 & autophagy & $\begin{array}{l}\text { Interacts with OPTN, inhibits } \\
\text { aoutophagy }\end{array}$ \\
\hline LSM4 & NM_012321 & 45.62 & splicing & Sm/LSm spliceosome \\
\hline CSPG3 & NM_004386 & 45.74 & neuronal function & $\begin{array}{l}\text { Chondroitin sulfate proteoglycans, } \\
\text { regulate axon outgrowth }\end{array}$ \\
\hline CKAP4 & NM_006825 & 46.20 & miscellaneous & \\
\hline C20ORF14 & NM_012469 & 46.55 & splicing & U5 spliceosome \\
\hline NRF & NM_017544 & 47.40 & miscellaneous & RNA binding \\
\hline FLJ10613 & NM_019067 & 47.63 & miscellaneous & nucleocyptoplasmic shuttling \\
\hline RAB3IP & NM_022456 & 49.74 & autophagy & autophagy inhibitor \\
\hline TCF21 & NM_003206 & 50.02 & transcription factor & \\
\hline ABLIM1 & NM_002313 & 51.36 & neuronal function & actin binding, axonogenesis \\
\hline SUPT6H & NM_003170 & 51.52 & transcription factor & \\
\hline HIVEP3 & NM_024503 & 51.69 & miscellaneous & \\
\hline SLC25A14 & NM_003951 & 51.73 & mitochondria & $\begin{array}{l}\text { mitochondrial uncoupling protein } \\
\text { UCP5 }\end{array}$ \\
\hline ASB8 & NM_024095 & 53.08 & proteasome & E3 ligase \\
\hline MGC35048 & NM_153208 & 53.45 & neuronal function & Alzheimer's Disease risk loci \\
\hline FLJ43339 & NM_207380 & 54.14 & miscellaneous & RNA binding \\
\hline C20ORF40 & NM_144703 & 55.07 & LSM protein & shared protein domain with Ataxin-2 \\
\hline DNM3 & NM_015569 & 55.25 & neuronal function & $\begin{array}{l}\text { potential genetic modifier in } \\
\text { Parkinson's disease }\end{array}$ \\
\hline LETM1 & NM_012318 & 55.26 & mitochondria & $\begin{array}{l}\text { oxidative stress, mitochondrial } \\
\mathrm{Ca} 2+/ \mathrm{H}+\text { antiporter }\end{array}$ \\
\hline THUMPD1 & NM_017736 & 58.61 & miscellaneous & potential splicing regulator \\
\hline RTN4R & NM_023004 & 59.10 & neuronal function & axon sprouting and regeneration \\
\hline C2ORF15 & NM_144706 & 62.04 & miscellaneous & potential splicing regulator \\
\hline ZNF385 & NM_015481 & 62.22 & miscellaneous & potential splicing regulator \\
\hline FLJ14494 & NM_032795 & 62.41 & mitochondria & $\begin{array}{l}\text { oxidative stress, pseudouridylation, } \\
\text { RPUSD4 }\end{array}$ \\
\hline FBXW5 & NM_178225 & 63.31 & autophagy & \\
\hline CAMK1 & NM_003656 & 63.94 & miscellaneous & \\
\hline C13ORF22 & NM_005800 & 65.32 & splicing & U5 spliceosome \\
\hline ASB9 & NM_024087 & 65.81 & proteasome & E3 ligase \\
\hline
\end{tabular}




\begin{tabular}{|c|c|c|c|c|}
\hline METTL3 & NM_019852 & 66.83 & miscellaneous & $\mathrm{m}(6) \mathrm{A}$ methyltransferase \\
\hline RGS16 & NM_002928 & 69.12 & miscellaneous & \\
\hline
\end{tabular}

Table S1: List of High Confidence Hits. \% HiBiT signal relative to control was calculated from data collected in the secondary screen. Two biological replicates were performed for HiBiT signal and averaged and then normalized to the average signal from the non-targeting control wells run in parallel.

A

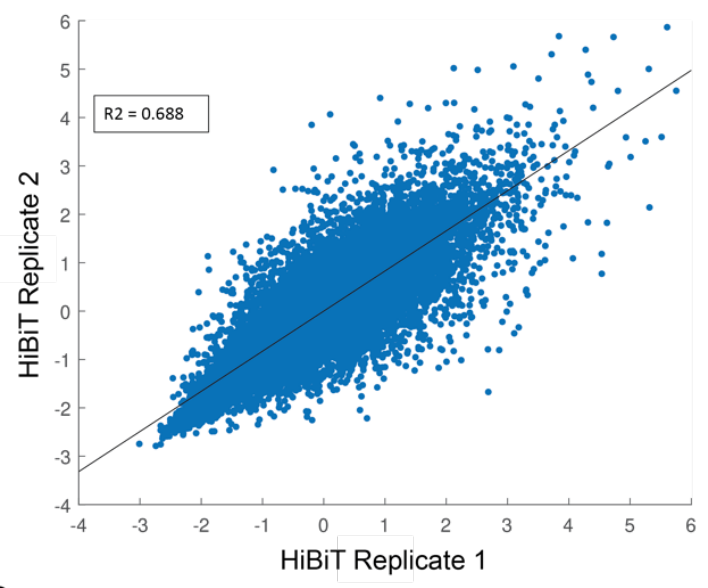

B

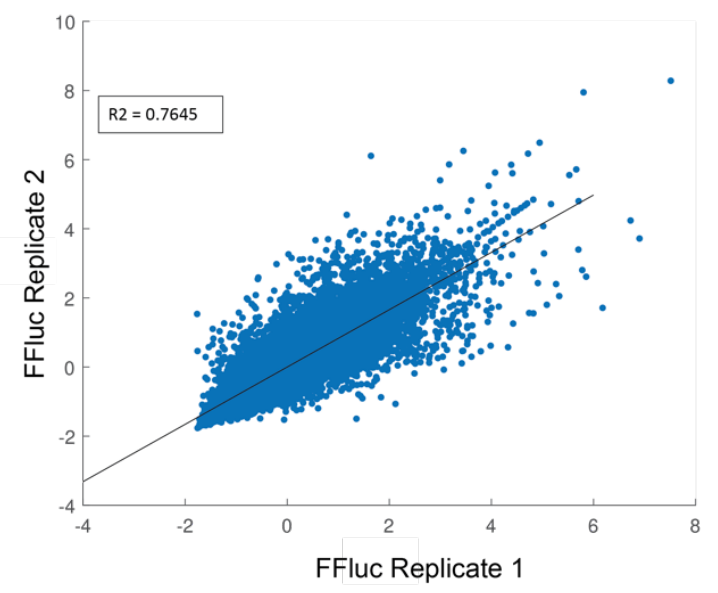

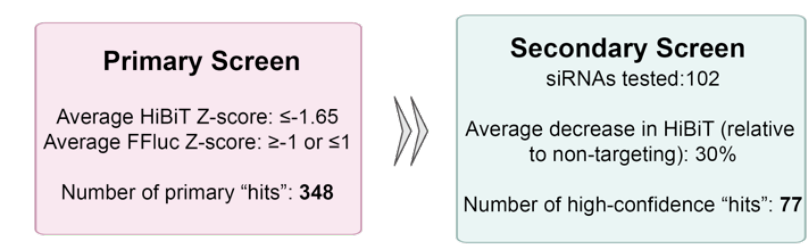

Figure S1: Ataxin-2 screen results and filters. Plots of the primary screen HiBiT data (A) and FFLuc data (B) for both replicates. $\mathrm{R}^{2}=0.688$ and 0.7645 , respectively. (C) Filters applied to screen results to determine the highest confidence ataxin- 2 regulators. 
A

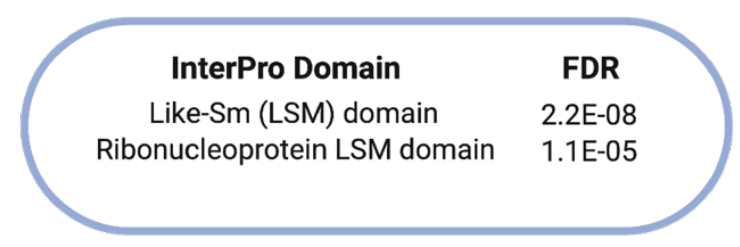

B

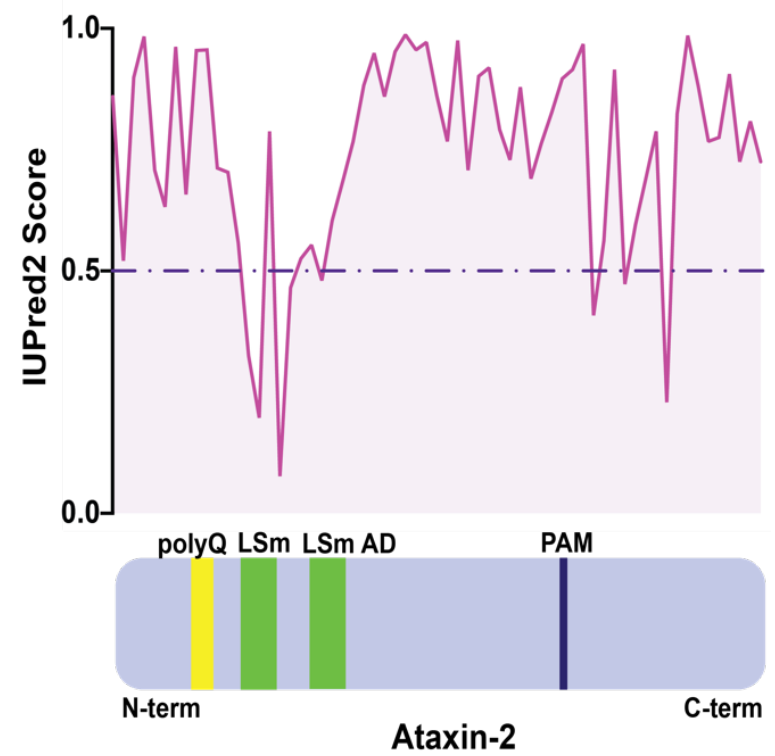

Figure S2: Shared protein domain between ataxin-2 and its regulators. (A) InterPro domain enrichment of primary screen hits. (B) Bottom: representation of ataxin-2 protein domains including the poly-glutamine stretch (polyQ), the LSm and LSm-associated (LSm AD) domains, and the PABP-interacting motif (PAM). Top: graph of the IUPred2 score, a prediction of protein disorder, for the amino acid sequence of ataxin-2. 
A

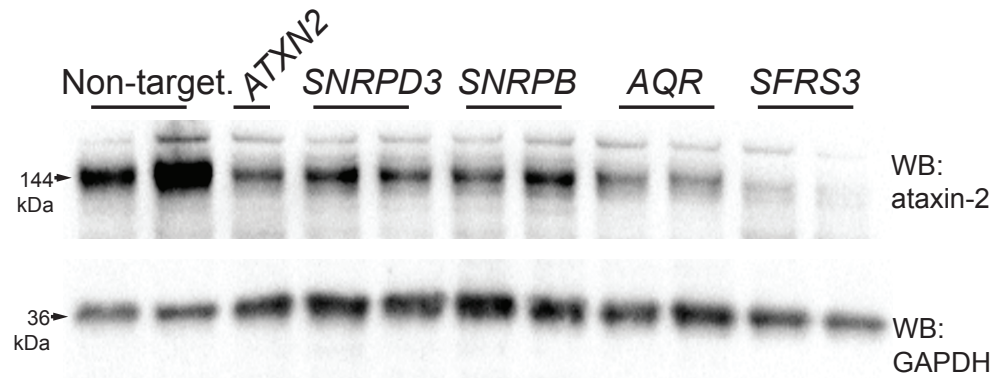

B RT-qPCR

$\square$ Non-targeting Target siRNA

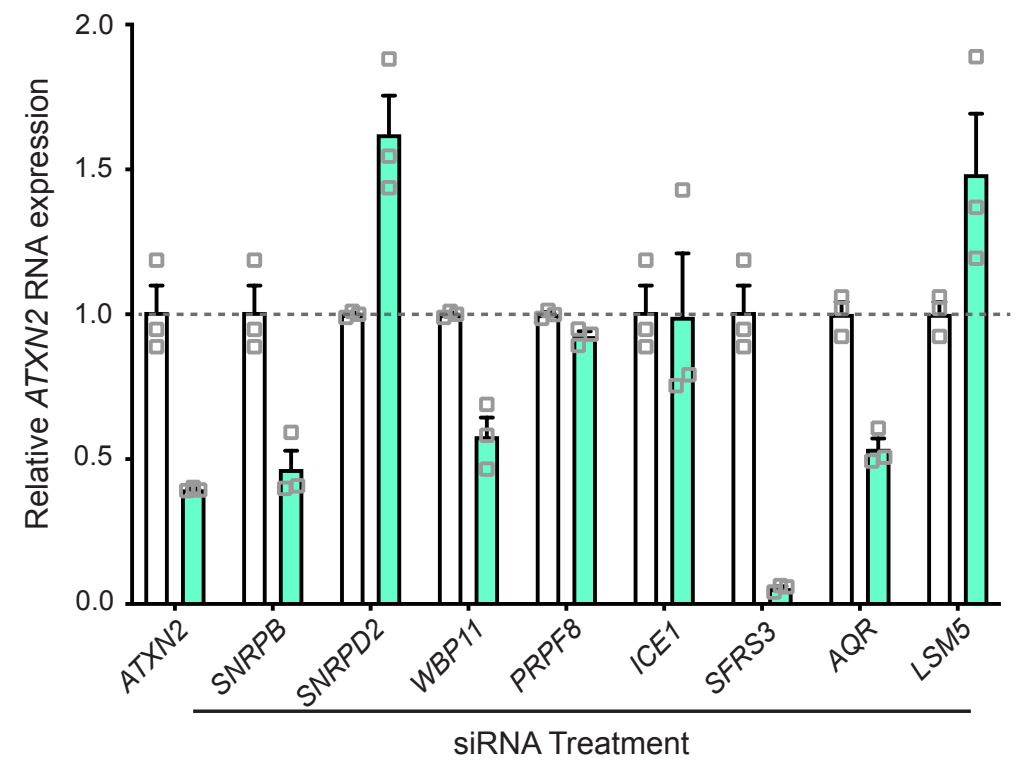

Figure S3: Further validation of screen results. (A) Immunoblot of ataxin-2 and GAPDH levels after siRNA treatment in unedited HEK293T cell lysates. (B) RT-qPCR on RNA from cells treated with non-targeting siRNA or siRNA targeting various splicing factors. We probed for ATXN2 transcript along with $A C T B$ for normalization. Two-way ANOVA with multiple comparisons: $W B P 11$ and $A Q R, \mathrm{p} \leq 0.05$. LSM5 and $S N R P B, \mathrm{p} \leq 0.01$. ATXN2 and SNRPD2, $\mathrm{p} \leq 0.001$. SFRS3, $\mathrm{p} \leq 0.0001$. Error bars represent \pm SEM. 
A

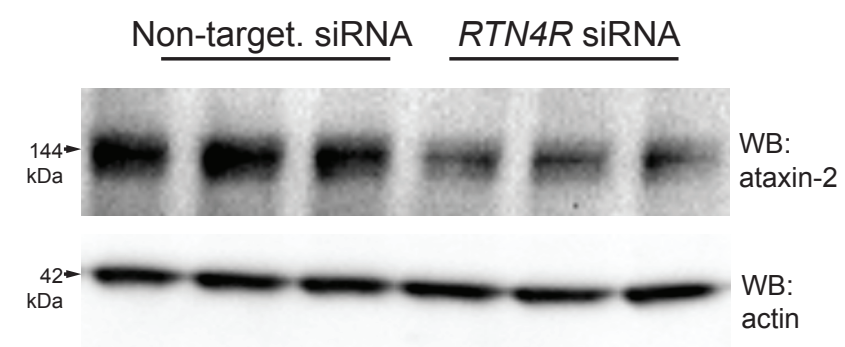

Sh-SY5Y Neuroblastoma line
B

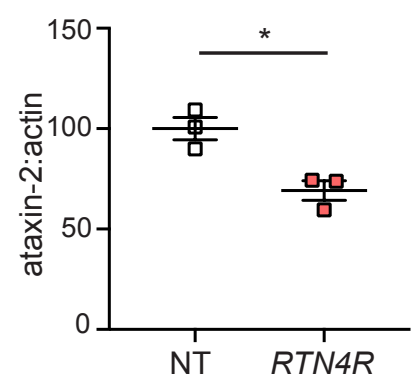

D

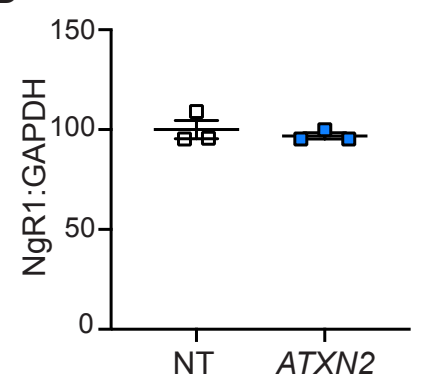

Figure S4: Further validation of $R T N 4 R$ as a regulator of ataxin-2. (A) Immunoblot on SHSY5Y cell lysates after RTN4R siRNA treatment. Ataxin-2 levels are quantified in (B). (C) Immunoblot on HEK293T cell lysates after ATXN2 siRNA treatment. RTN4/NoGo-Receptor levels are quantified in (D). Student's t-test. $* \mathrm{p} \leq 0.05$. Error bars represent $\pm \mathrm{SEM}$. 


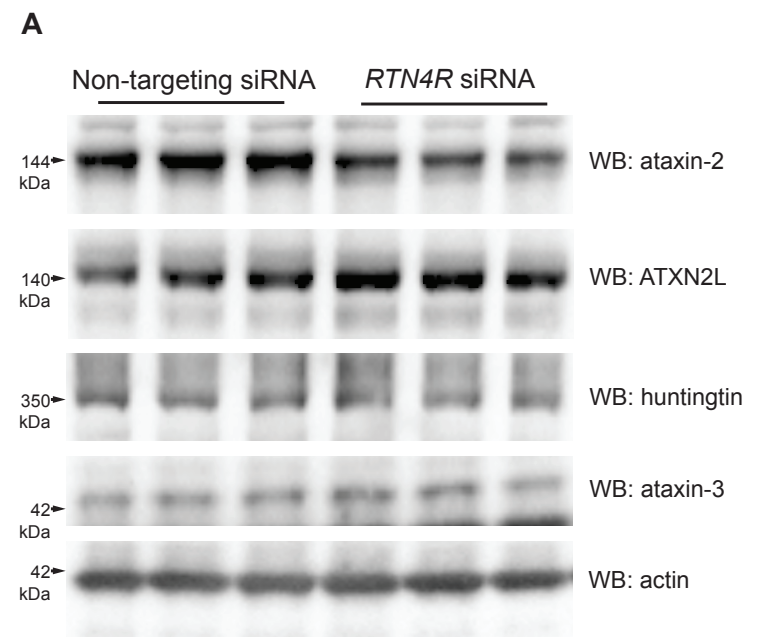

\section{B}

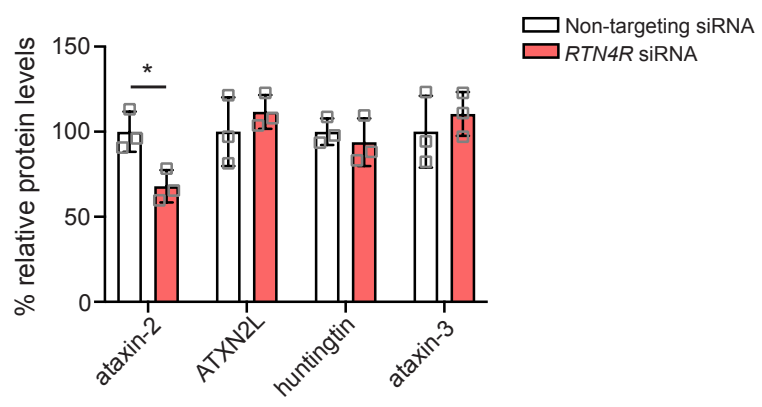

Figure S5: Knockdown of RTN4R does not alter the expression of other polyQ proteins or

ATXN2L. (A) Immunoblot of ATXN2L (Ataxin-2 paralog) and polyQ disease proteins ataxin-2, huntingtin, and ataxin-3 after RTN4R siRNA treatment in unedited HEK293T cell lysates. Quantified in (B). Student's t-test. *p $\leq 0.05$. Error bars represent \pm SEM.

A
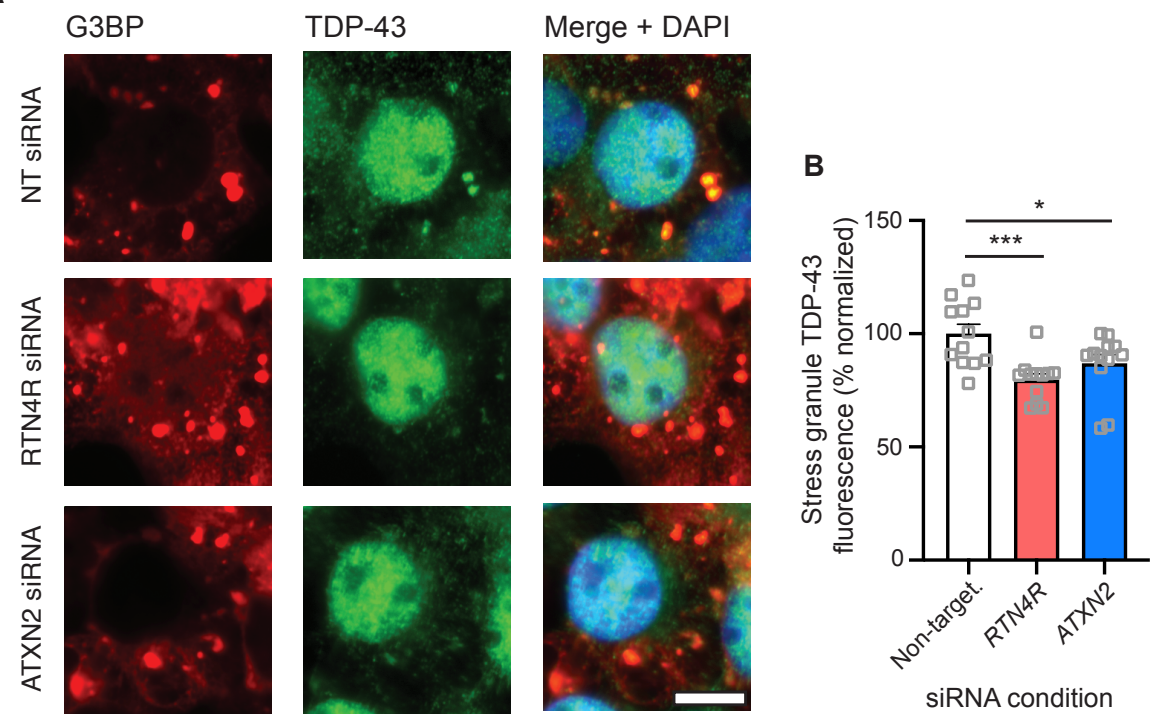
Figure S6: Knockdown of $R T N 4 R$ reduces TDP-43 localization to stress granules. (A) We treated HEK293T cells with siRNA, and subsequently treated for 30 minutes with $0.5 \mathrm{mM}$ sodium arsenite to induce stress granules. We probed for TDP-43 and the stress granule marker G3BP via immunocytochemistry. Scale bar $=10 \mu \mathrm{m}$. The average fluorescence of TDP-43 in stress granules is quantified in (B). One-way ANOVA, ${ }^{*} \mathrm{p} \leq 0.05, * * * \mathrm{p} \leq 0.001$. Error bars represent $\pm \mathrm{SEM}$.

A

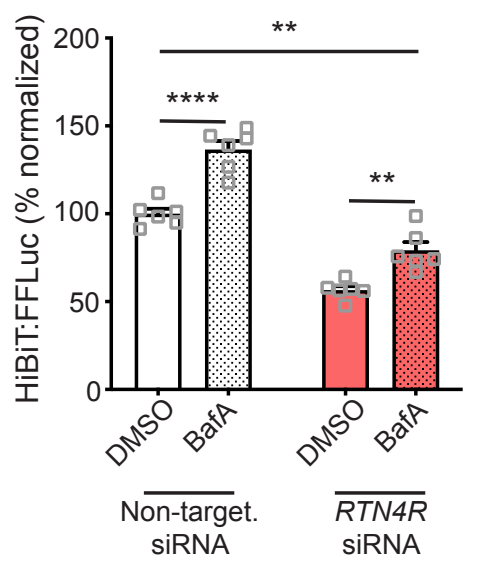

B

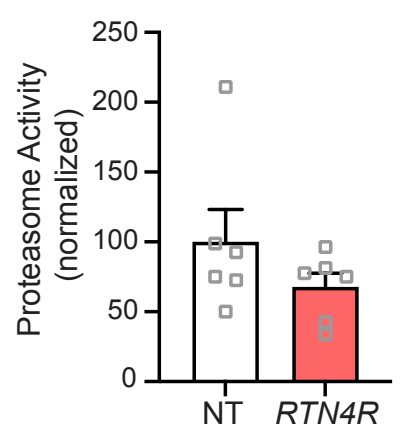

Figure S7: Knockdown of $R T N 4 R$ does not decrease ataxin-2 through autophagy pathways and does not increase general proteasome activity. (A) We treated ataxin-2-HiBiT cells with siRNA, then treated for $24 \mathrm{hr}$ with autophagy inhibitor Bafilomycin A1 or DMSO. We performed a luciferase assay to measure HiBiT activity. (B) Proteasome activity assay (utilizing Suc-LLVYAMC as a substrate) in HEK293T cell lysates after RTN4R siRNA treatment. Two-way ANOVA with multiple comparisons. $* * \mathrm{p} \leq 0.01, * * * * \mathrm{p} \leq 0.0001$. Error bars represent $\pm \mathrm{SEM}$. 


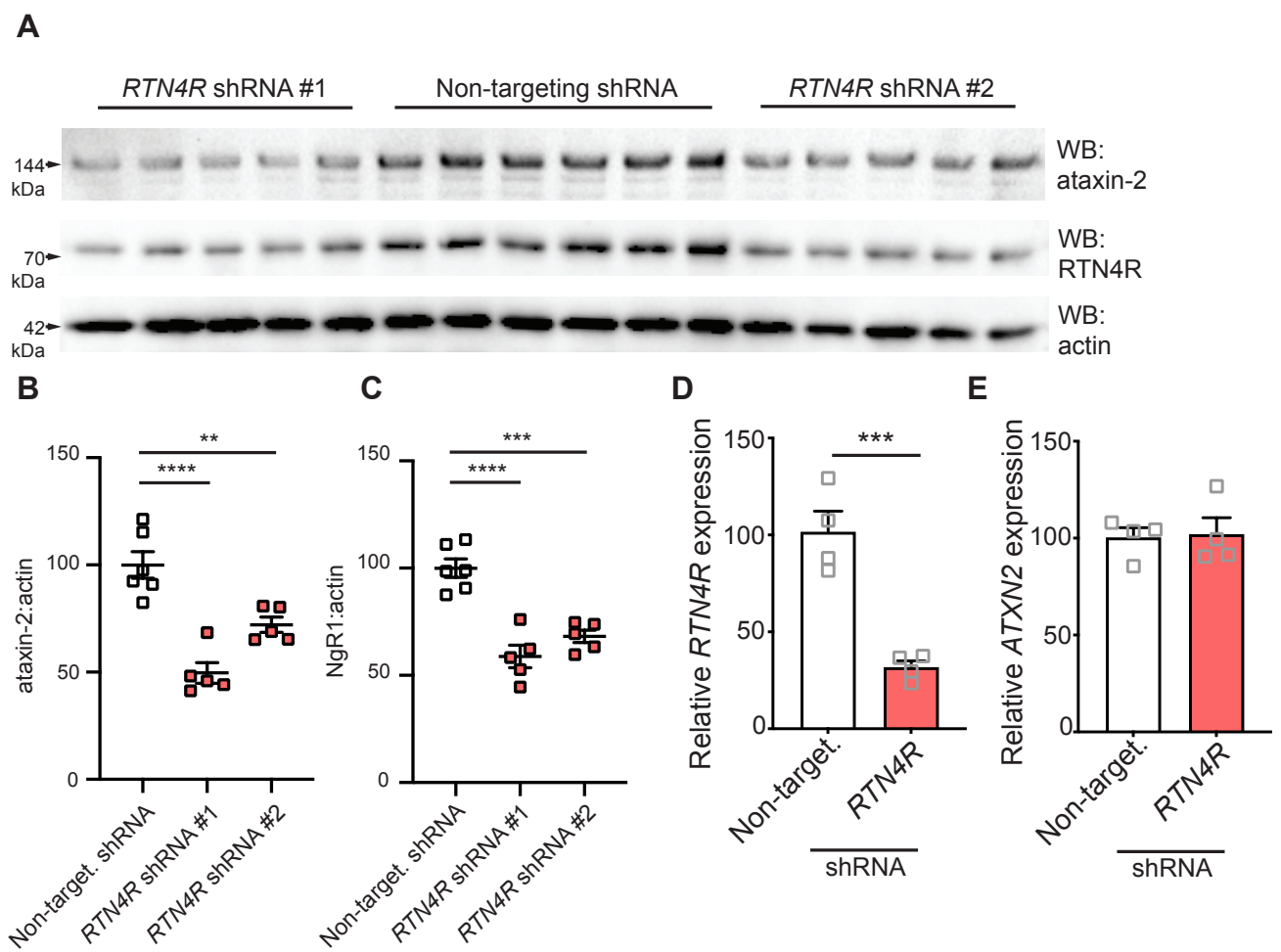

Figure S8: Full immunoblot on neuron lysates treated with two different shRNA constructs targeting $R T N 4 R$ and RT-qPCR on shRNA-treated primary neurons. (A) Immunoblot of ataxin-2 and RTN4/NoGo-Receptor levels after 12 days of shRNA treatment in cortical neuron cultures. We used two shRNA constructs targeting different regions of $R T N 4 R$, along with a nontargeting shRNA construct. Quantification of ataxin-2 (B) and RTN4/NoGo-Receptor (C) levels. (D), (E), We performed RT-qPCR on RNA from shRNA-treated mouse neurons. We probed for $R T N 4 R$ transcript (D) and $A T X N 2$ transcript (E) along with $G A P D H$ as a housekeeping gene for normalization. Student's t-test. $* * \mathrm{p} \leq 0.01, * * * \mathrm{p} \leq 0.001, * * * * \mathrm{p} \leq 0.0001$. Error bars represent \pm SEM.

\section{Acknowledgments}

This work was supported by NIH grants R35NS097263(10) (A.D.G.); R35NS097283 (S.M.S.); F32NS116208 (C.M.R.); 5T32NS007280 (G.L.J.); 2T32AG047126-06A1 (T.A.); the Robert Packard Center for ALS Research at Johns Hopkins (A.D.G.); Target ALS (A.D.G.); and the Brain Rejuvenation Project of the $\mathrm{Wu}$ Tsai Neurosciences Institute (A.D.G.). G.K. is supported by a fellowship from the Stanford Knight-Hennessy Scholars Program. T.A. is supported by a 
fellowship from the Takeda Science Foundation. The whole genome siRNA screen was performed with the expertise and resources in the High-Throughput Bioscience Center at Stanford University. Some of the figures were created with BioRender.com.

Competing interests: A.D.G. is a scientific founder of Maze Therapeutics. S.M.S. is a founder and equity holder in ReNetX Bio, Inc. which seeks clinical development of the decoy receptor, NgR1Fc (AXER-204), for chronic spinal cord injury treatment. Stanford University has filed a provisional patent $(63 / 286,436)$ on methods described in this manuscript for treatment of neurodegenerative diseases through the inhibition of ataxin-2.

\section{Data and Code Availability}

The datasets generated during the current study are available from the corresponding author upon request.

\section{References}

2013. The Genotype-Tissue Expression (GTEx) project. Nat Genet, 45, 580-5.

AKBIK, F. V., BHAGAT, S. M., PATEL, P. R., CAFFERTY, W. B. \& STRITTMATTER, S. M. 2013. Anatomical plasticity of adult brain is titrated by Nogo Receptor 1. Neuron, 77, 859-66.

ANDRUSIAK, M. G., SHARIFNIA, P., LYU, X., WANG, Z., DICKEY, A. M., WU, Z., CHISHOLM, A. D. \& JIN, Y. 2019. Inhibition of Axon Regeneration by Liquid-like TIAR-2 Granules. Neuron, 104, 290-304.e8.

BECKER, L. A., HUANG, B., BIERI, G., MA, R., KNOWLES, D. A., JAFAR-NEJAD, P., MESSING, J., KIM, H. J., SORIANO, A., AUBURGER, G., PULST, S. M., TAYLOR, J. P., RIGO, F. \& GITLER, A. D. 2017. Therapeutic reduction of ataxin-2 extends lifespan and reduces pathology in TDP-43 mice. Nature, 544, 367-371.

BHAGAT, S. M., BUTLER, S. S., TAYLOR, J. R., MCEWEN, B. S. \& STRITTMATTER, S. M. 2016. Erasure of fear memories is prevented by Nogo Receptor 1 in adulthood. Mol Psychiatry, 21, 1281-9.

BIERI, G., BRAHIC, M., BOUSSET, L., COUTHOUIS, J., KRAMER, N. J., MA, R., NAKAYAMA, L., MONBUREAU, M., DEFENSOR, E., SCHÜLE, B., SHAMLOO, M., MELKI, R. \& GITLER, A. D. 2019. LRRK2 modifies $\alpha$-syn pathology and spread in mouse models and human neurons. Acta Neuropathol, 137, 961-980.

BROS-FACER, V., KRULL, D., TAYLOR, A., DICK, J. R., BATES, S. A., CLEVELAND, M. S., PRINJHA, R. K. \& GREENSMITH, L. 2014. Treatment with an antibody directed against Nogo-A delays disease progression in the SOD1G93A mouse model of Amyotrophic lateral sclerosis. Hum Mol Genet, 23, 4187-200. 
CHIVATAKARN, O., KANEKO, S., HE, Z., TESSIER-LAVIGNE, M. \& GIGER, R. J. 2007. The Nogo-66 receptor NgR1 is required only for the acute growth cone-collapsing but not the chronic growth-inhibitory actions of myelin inhibitors. $J$ Neurosci, 27, 7117-24.

CHONG, Z. S., OHNISHI, S., YUSA, K. \& WRIGHT, G. J. 2018. Pooled extracellular receptorligand interaction screening using CRISPR activation. Genome Biol, 19, 205.

DIXON, A. S., SCHWINN, M. K., HALL, M. P., ZIMMERMAN, K., OTTO, P., LUBBEN, T. H., BUTLER, B. L., BINKOWSKI, B. F., MACHLEIDT, T., KIRKLAND, T. A., WOOD, M. G., EGGERS, C. T., ENCELL, L. P. \& WOOD, K. V. 2016. NanoLuc Complementation Reporter Optimized for Accurate Measurement of Protein Interactions in Cells. ACS Chem Biol, 11, 400-8.

DOMENICONI, M., CAO, Z., SPENCER, T., SIVASANKARAN, R., WANG, K., NIKULINA, E., KIMURA, N., CAI, H., DENG, K., GAO, Y., HE, Z. \& FILBIN, M. 2002. Myelinassociated glycoprotein interacts with the Nogo66 receptor to inhibit neurite outgrowth. Neuron, 35, 283-90.

ELDEN, A. C., KIM, H. J., HART, M. P., CHEN-PLOTKIN, A. S., JOHNSON, B. S., FANG, X., ARMAKOLA, M., GESER, F., GREENE, R., LU, M. M., PADMANABHAN, A., CLAY-FALCONE, D., MCCLUSKEY, L., ELMAN, L., JUHR, D., GRUBER, P. J., RÜB, U., AUBURGER, G., TROJANOWSKI, J. Q., LEE, V. M., VAN DEERLIN, V. M., BONINI, N. M. \& GITLER, A. D. 2010. Ataxin-2 intermediate-length polyglutamine expansions are associated with increased risk for ALS. Nature, 466, 1069-75.

FINK, K. L., STRITTMATTER, S. M. \& CAFFERTY, W. B. 2015. Comprehensive Corticospinal Labeling with mu-crystallin Transgene Reveals Axon Regeneration after Spinal Cord Trauma in ngr1-/- Mice. J Neurosci, 35, 15403-18.

FOURNIER, A. E., GRANDPRE, T. \& STRITTMATTER, S. M. 2001. Identification of a receptor mediating Nogo-66 inhibition of axonal regeneration. Nature, 409, 341-6.

GRANDPRÉ, T., LI, S. \& STRITTMATTER, S. M. 2002. Nogo-66 receptor antagonist peptide promotes axonal regeneration. Nature, 417, 547-51.

HE, W. \& PARKER, R. 2000. Functions of Lsm proteins in mRNA degradation and splicing. Curr Opin Cell Biol, 12, 346-50.

JOKIC, N., GONZALEZ DE AGUILAR, J. L., DIMOU, L., LIN, S., FERGANI, A., RUEGG, M. A., SCHWAB, M. E., DUPUIS, L. \& LOEFFLER, J. P. 2006. The neurite outgrowth inhibitor Nogo-A promotes denervation in an amyotrophic lateral sclerosis model. EMBO Rep, 7, 1162-7.

KIM, J. E., LIU, B. P., PARK, J. H. \& STRITTMATTER, S. M. 2004. Nogo-66 receptor prevents raphespinal and rubrospinal axon regeneration and limits functional recovery from spinal cord injury. Neuron, 44, 439-51.

LAGIER-TOURENNE, C., POLYMENIDOU, M. \& CLEVELAND, D. W. 2010. TDP-43 and FUS/TLS: emerging roles in RNA processing and neurodegeneration. Hum Mol Genet, 19, R46-64.

LIU-YESUCEVITZ, L., BASSELL, G. J., GITLER, A. D., HART, A. C., KLANN, E., RICHTER, J. D., WARREN, S. T. \& WOLOZIN, B. 2011. Local RNA translation at the synapse and in disease. $J$ Neurosci, 31, 16086-93.

MCFARLAND, J. M., HO, Z. V., KUGENER, G., DEMPSTER, J. M., MONTGOMERY, P. G., BRYAN, J. G., KRILL-BURGER, J. M., GREEN, T. M., VAZQUEZ, F., BOEHM, J. S., GOLUB, T. R., HAHN, W. C., ROOT, D. E. \& TSHERNIAK, A. 2018. Improved 
estimation of cancer dependencies from large-scale RNAi screens using model-based normalization and data integration. Nature Communications, 9, 4610.

MCGEE, A. W., YANG, Y., FISCHER, Q. S., DAW, N. W. \& STRITTMATTER, S. M. 2005. Experience-driven plasticity of visual cortex limited by myelin and Nogo receptor. Science, 309, 2222-6.

MEYERS, R. M., BRYAN, J. G., MCFARLAND, J. M., WEIR, B. A., SIZEMORE, A. E., XU, H., DHARIA, N. V., MONTGOMERY, P. G., COWLEY, G. S., PANTEL, S., GOODALE, A., LEE, Y., ALI, L. D., JIANG, G., LUBONJA, R., HARRINGTON, W. F., STRICKLAND, M., WU, T., HAWES, D. C., ZHIVICH, V. A., WYATT, M. R., KALANI, Z., CHANG, J. J., OKAMOTO, M., STEGMAIER, K., GOLUB, T. R., BOEHM, J. S., VAZQUEZ, F., ROOT, D. E., HAHN, W. C. \& TSHERNIAK, A. 2017. Computational correction of copy number effect improves specificity of CRISPR-Cas9 essentiality screens in cancer cells. Nature Genetics, 49, 1779-1784.

MONTANI, L., GERRITS, B., GEHRIG, P., KEMPF, A., DIMOU, L., WOLLSCHEID, B. \& SCHWAB, M. E. 2009. Neuronal Nogo-A modulates growth cone motility via RhoGTP/LIMK1/cofilin in the unlesioned adult nervous system. J Biol Chem, 284, 10793807.

PAULSON, H. L., SHAKKOTTAI, V. G., CLARK, H. B. \& ORR, H. T. 2017. Polyglutamine spinocerebellar ataxias - from genes to potential treatments. Nat Rev Neurosci, 18, 613626.

RICHING, K. M., MAHAN, S., CORONA, C. R., MCDOUGALL, M., VASTA, J. D., ROBERS, M. B., URH, M. \& DANIELS, D. L. 2018. Quantitative Live-Cell Kinetic Degradation and Mechanistic Profiling of PROTAC Mode of Action. ACS Chem Biol, 13, 2758-2770.

SATO, Y., IKETANI, M., KURIHARA, Y., YAMAGUCHI, M., YAMASHITA, N., NAKAMURA, F., ARIE, Y., KAWASAKI, T., HIRATA, T., ABE, T., KIYONARI, H., STRITTMATTER, S. M., GOSHIMA, Y.\& TAKEI, K. 2011. Cartilage acidic protein1B (LOTUS), an endogenous Nogo receptor antagonist for axon tract formation. Science, 333, 769-73.

SCHWAB, M. E. 2010. Functions of Nogo proteins and their receptors in the nervous system. Nat Rev Neurosci, 11, 799-811.

SCHWAB, M. E. \& STRITTMATTER, S. M. 2014. Nogo limits neural plasticity and recovery from injury. Curr Opin Neurobiol, 27, 53-60.

SCOLES, D. R., MEERA, P., SCHNEIDER, M. D., PAUL, S., DANSITHONG, W., FIGUEROA, K. P., HUNG, G., RIGO, F., BENNETT, C. F., OTIS, T. S. \& PULST, S. M. 2017. Antisense oligonucleotide therapy for spinocerebellar ataxia type 2. Nature, 544, 362-366.

SCOLES, D. R. \& PULST, S. M. 2018. Spinocerebellar Ataxia Type 2. Adv Exp Med Biol, 1049, 175-195.

TAYLOR, J. P., BROWN, R. H., JR. \& CLEVELAND, D. W. 2016. Decoding ALS: from genes to mechanism. Nature, 539, 197-206.

THOMAS, R., FAVELL, K., MORANTE-REDOLAT, J., POOL, M., KENT, C., WRIGHT, M., DAIGNAULT, K., FERRARO, G. B., MONTCALM, S., DUROCHER, Y., FOURNIER, A., PEREZ-TUR, J. \& BARKER, P. A. 2010. LGI1 is a Nogo receptor 1 ligand that antagonizes myelin-based growth inhibition. J Neurosci, 30, 6607-12. 
TONG, Z., SEGURA-FELIU, M., SEIRA, O., HOMS CORBERA, A., ANTONIO, J., RÍO, J., ADE, J. \& SAMITIER, J. 2015. A microfluidic neuronal platform for neuron axotomy and controlled regenerative studies. RSC Advances, 5, 0-1.

WANG, J., MIAO, Y., WICKLEIN, R., SUN, Z., WANG, J., JUDE, K. M., FERNANDES, R. A., MERRILL, S. A., WERNIG, M., GARCIA, K. C. \& SÜDHOF, T. C. RTN4/NoGoreceptor binding to BAI adhesion-GPCRs regulates neuronal development. Cell.

WANG, K. C., KIM, J. A., SIVASANKARAN, R., SEGAL, R. \& HE, Z. 2002. P75 interacts with the Nogo receptor as a co-receptor for Nogo, MAG and OMgp. Nature, 420, 74-8.

WANG, X., DUFFY, P., MCGEE, A. W., HASAN, O., GOULD, G., TU, N., HAREL, N. Y., HUANG, Y., CARSON, R. E., WEINZIMMER, D., ROPCHAN, J., BENOWITZ, L. I., CAFFERTY, W. B. \& STRITTMATTER, S. M. 2011. Recovery from chronic spinal cord contusion after Nogo receptor intervention. Ann Neurol, 70, 805-21.

WANG, X., ZHOU, T., MAYNARD, G. D., TERSE, P. S., CAFFERTY, W. B., KOCSIS, J. D. \& STRITTMATTER, S. M. 2020. Nogo receptor decoy promotes recovery and corticospinal growth in non-human primate spinal cord injury. Brain, 143, 1697-1713.

YANG, Y. S., HAREL, N. Y. \& STRITTMATTER, S. M. 2009. Reticulon-4A (Nogo-A) redistributes protein disulfide isomerase to protect mice from SOD1-dependent amyotrophic lateral sclerosis. J Neurosci, 29, 13850-9.

ZHANG, L., ZHENG, S., WU, H., WU, Y., LIU, S., FAN, M. \& ZHANG, J. 2009. Identification of BLyS (B lymphocyte stimulator), a non-myelin-associated protein, as a functional ligand for Nogo-66 receptor. J Neurosci, 29, 6348-52. 